FHWA/IN/JTRP-2000/13

\author{
Final Report
}

\title{
A FIELD STUDY OF SCOUR-MONITORING DEVICES FOR INDIANA STREAMS
}

\author{
Thomas Cooper \\ H.-L. Chen \\ Dennis Lyn \\ A. Ramachandra Rao \\ A. G. Altschaeffl
}

October 2000 
Final Report

\title{
A Field Study of Scour-Monitoring Devices for Indiana Streams
}

FHWA/IN/JTRP-2000/13

\author{
by \\ Thomas Cooper \\ H.-L. Chen \\ Dennis A. Lyn \\ A. Ramachandra Rao \\ A. G. Altschaeffl \\ Purdue University \\ School of Civil Engineering \\ Joint Transportation Research Program \\ Project No. C-36-62I \\ File No. 9-8-9 \\ Prepared in cooperation with the \\ Indiana Department of Transportation and the \\ U.S. Department of Transportation \\ Federal Highway Administration
}

The contents of this report reflect the views of the author who is responsible for the facts and the accuracy of the data presented herein. The contents do not necessarily reflect the official views or policies of the Indiana Department of Transportation or the Federal Highway Administration at the time of publication. This report does not constitute a standard, specification, or regulation.

Purdue University

West Lafayette, Indiana 47907

October 2000 
TECHNICAL REPORT STANDARD TITLE PAGE

\begin{tabular}{|c|c|c|}
\hline $\begin{array}{l}\text { 1. Report No. } \\
\text { FHWA/IN/JTRP-2000/13 }\end{array}$ & 2. Government Accession No. & 3. Recipient's Catalog No. \\
\hline \multirow{2}{*}{\multicolumn{2}{|c|}{$\begin{array}{l}\text { 4. Title and Subtitle } \\
\text { A Field Study of Scour-Monitoring Devices for Indiana Streams }\end{array}$}} & $\begin{array}{l}\text { 5. } \text { Report Date } \\
\text { October } 2000\end{array}$ \\
\hline & & 6. Performing Organization Code \\
\hline \multicolumn{2}{|c|}{$\begin{array}{l}\text { 7. Author(s) } \\
\text { Thomas Cooper, H.-L. Chen, Dennis Lyn, A. Ramachandra Rao, and A. G. Altschaeffl }\end{array}$} & $\begin{array}{l}\text { 8. Performing Organization Report No. } \\
\text { FHWA/IN/JTRP-2000/13 }\end{array}$ \\
\hline \multirow{2}{*}{\multicolumn{2}{|c|}{$\begin{array}{l}\text { 9. Performing Organization Name and Address } \\
\text { Joint Transportation Research Program } \\
\text { 1284 Civil Engineering Building } \\
\text { Purdue University } \\
\text { West Lafayette, Indiana } 47907-1284\end{array}$}} & 10. Work Unit No. \\
\hline & & $\begin{array}{l}\text { 11. Contract or Grant No. } \\
\text { SPR-2149 }\end{array}$ \\
\hline \multirow{2}{*}{\multicolumn{2}{|c|}{$\begin{array}{l}\text { 12. Sponsoring Agency Name and Address } \\
\text { Indiana Department of Transportation } \\
\text { State Office Building } \\
100 \text { North Senate Avenue } \\
\text { Indianapolis, IN } 46204\end{array}$}} & $\begin{array}{c}\text { 13. Type of Report and Period Covered } \\
\text { Final Report }\end{array}$ \\
\hline & & 14. Sponsoring Agency Code \\
\hline \multicolumn{3}{|l|}{ 15. Supplementary Notes } \\
\hline
\end{tabular}

\section{Abstract}

INDOT is considering the deployment of fixed scour-monitoring instrumentation as part of a systematic response to the problem of scour around bridge piers. Within a larger study of the efficacy of and the problems to be encountered with such instrumentation, a project was undertaken in which two different types of scour monitoring devices were installed on piers at two different sites near Purdue University. The two devices, one based on a magnetic collar on a rod driven into the streambed, the other based on a sonar or acoustic principle, were developed with funding by the FHWA/NCHRP, and their use is being actively promoted by these federal agencies.

This report is divided into three main sections. First, in Chapter 2, the devices are described and their principles of operation are briefly outlined. Deviations from the standard configuration are highlighted. In Chapter 3, the installation procedure followed is described, and a report of the important events during the course of the field component of the project is given generally. The procedure for downloading the field data collected is briefly dealt with, together with a description of the format of the data collected. A sample of the data so far obtained forms the basis of the discussion in Chapter 4 of the performance of the scour monitoring devices. The important conclusions gained from the field study as well as the questions still open are summarized in Chapter 5. The devices do show promise as being effective for continuously monitoring the local scour around a bridge pier. The long-term survivability of the monitors in the Indiana stream environment, where woody debris is prevalent with no countermeasures taken, remains still to be proven..

\section{Key Words}

pier scour, scour-monitoring, field study, bridge hydraulics.
18. Distribution Statement

No restrictions. This document is available to the public through the National Technical Information Service, Springfield, VA 22161

\begin{tabular}{|c|c|c|c|}
\hline 19. Security Classif. (of this report) & 20. Security Classif. (of this page) & 21. No. of Pages & 22. Price \\
Unclassified & Unclassified & 46 & \\
\hline
\end{tabular}




\section{TECHNICAL Summary}

INDOT Research

Technology Transfer and Project Implementation Information

TRB Subject Code: 22-2 Bridge and Culvert Hydraulics

October 2000

Publication No.: FHWA/IN/JTRP-2000/13, SPR-2149

Final Report

\section{A Field Study of Scour-Monitoring Devices for Indiana Streams}

\section{Introduction}

INDOT is considering the deployment of fixed scour-monitoring instrumentation as part of a systematic response to the problem of scour around bridge piers. Within a larger study of the efficacy of and the problems to be encountered with such instrumentation, a project was undertaken in which two different types of scour monitoring devices were installed on piers at two different sites near Purdue University. The two devices, one based on a magnetic collar on a rod driven into the streambed, the other based on a sonar or acoustic principle, were developed with funding by the FHWA/NCHRP, and their use is being actively promoted by these federal agencies. The two sites were the SR25 -Wildcat Creek crossing and the US52-Wabash R. crossing.

The first installation at the US52 Wabash R. site was completed in June 1997, but the sonar device failed a few days afterwards during the first flood. In January 1999, both devices at the US52 Wabash R. site and the magnetic-collar device at the SR25 Wildcat Creek site failed. As a result of the study of these failures, modifications were made to the original installation procedure with the aim of enhancing the survivability of the devices in Indiana streams. At the present time, only a sonar device remains at the US52 Wabash R. site, having been reinstalled in the summer of 1999; the magnetic-collar device is irrecoverably lost. The sonar device at the SR25 Wildcat Creek site is still functioning, but it has been severely hampered by the effect of woody debris accumulated at the pier on which the sonar is installed. The magnetic-collar device was repaired but its long-term survivability remains questionable.

\section{Findings}

As initially installed, the scourmonitoring devices would likely not be sufficiently robust for use in Indiana streams. Both types of devices have failed within the project period. It is believed however that with the modifications made to increase the protection of the cables and the sonar transceiver, the survivability of at least the sonar device has been enhanced. Nevertheless, since the modified sonar mount has only been installed in the field for less than a year, no definitive conclusions can as yet be made and an extension of the study period is recommended to be able to arrive at a more solid assessment. Woody debris in the flow poses the major problem for the scour monitors. The loss of one sonar transceiver and one magnetic-collar device is directly attributed to the effect of woody debris. Even apart from its impact on survivability, the problem of woody debris being trapped, or accumulating at bridge 
piers, must be dealt with if the scour monitors are to operate reliably. The sonar device at the SR25 Wildcat Creek has as yet not provided any useful data because of difficulties attributed to the effect of woody debris.

When operating under normal conditions, the two devices can give useful information regarding the development of local scour at the installation location. The readings from the two devices are generally consistent with one another, and also are plausible when considered in relation to the corresponding time series of hydrologic data. A more detailed study of the relationship between scour-monitoring data and hydrological data would be desirable with a larger sample of flood events.

\section{Contact}

For more information:

Dr. Dennis A. Lyn

Principal Investigator

School of Civil Engineering

Purdue University

West Lafayette, IN 47907

Phone: (765) 494-9615

Fax: (765) 496-1988

\section{Indiana Department of Transportation}

Division of Research

1205 Montgomery Street

P.O. Box 2279

West Lafayette, IN 47906

Phone: (765) 463-1521

Fax: (765) 497-1665

\section{Purdue University}

Joint Transportation Research Program

School of Civil Engineering

West Lafayette, IN 47907-1284

Phone: (765) 494-9310

Fax: (765) 496-1105 


\section{Table of Contents}

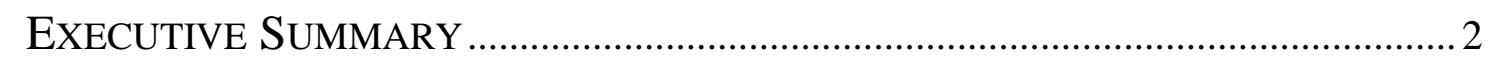

CHAPTER 1: INTRODUCTION AND SCOPE........................................3

1.1 LOCAL SCOUR AROUND BRIDGE PIERS ..............................................................

CHAPTER 2: THE SCOUR MONITORING DEVICES.......................5

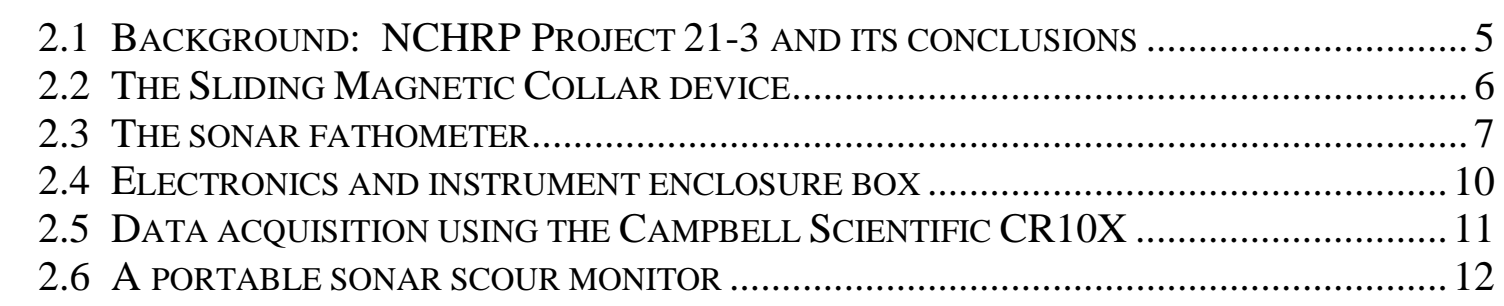

CHAPTER 3: INSTALLATION AND OPERATION OF THE .............. MONITORING DEVICES ....................................................................14

3.1 INSTALLATION OF DEVICES................................................................................... 14

3.1.1 The magnetic sliding collar device (with automated readout)................... 14

3.1.2 The sonar device................................................................................ 16

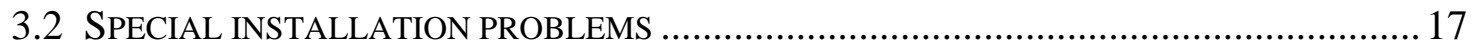

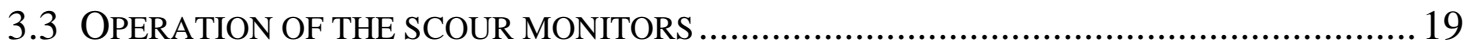

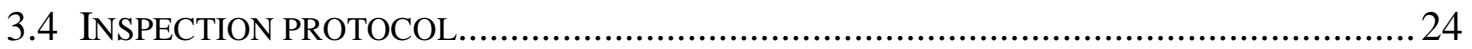

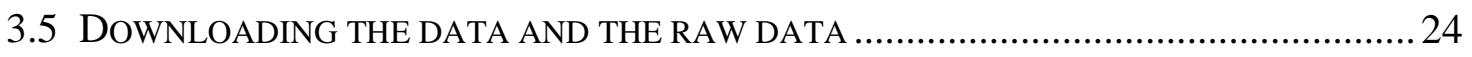

CHAPTER 4: THE SCOUR-MONITORING DATA ............................27

4.1 GENERAL CHARACTERISTICS OF THE SIGNAL FROM THE DEVICES $\ldots \ldots \ldots \ldots \ldots \ldots \ldots \ldots \ldots \ldots \ldots \ldots \ldots \ldots$

4.2 RELATION TO HYDROLOGICAL EVENTS: THE US52 WABASH R. SITE ......................29

4.3 RELATIONSHIP TO HYDROLOGIC EVENTS: THE SR25 WILDCAT CREEK SITE ........... 32

4.4 THE SCOUR-MONITORING DATA AND IMPLICATIONS FOR PIER SCOUR ..................... 33

SUMMARY AND CONCLUSIONS ............................................................35

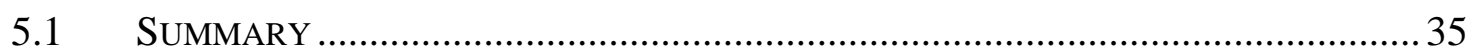

5.2 CONCLUSIONS AND RECOMMENDATIONS ............................................... 35

REFERENCES .....................................................................................................37

APPENDIX 1: CR10X DATA ACQUISITION PROGRAM .......................................... 38 


\section{Executive Summary}

INDOT is considering the deployment of fixed scour-monitoring instrumentation as part of a systematic response to the problem of scour around bridge piers. Within a larger study of the efficacy of and the problems to be encountered with such instrumentation, a project was undertaken in which two different types of scour monitoring devices were installed on piers at two different sites near Purdue University. The two devices, one based on a magnetic collar on a rod driven into the streambed, the other based on a sonar or acoustic principle, were developed with funding by the FHWA/NCHRP, and their use is being actively promoted by these federal agencies.

This report is divided into three main sections. Firstly, in Chap. 2, the devices are described and their principles of operation are briefly outlined. Deviations from the standard configuration are highlighted. In Chap. 3, the installation procedure followed is described, and a report of the important events during the course of the field component of the project is given general. The procedure for downloading the field data collected is briefly dealt with, together with a description of the format of the data collected. A sample of the data so far obtained forms the basis of the discussion in Chap. 4 of the performance of the scour monitoring devices. The important conclusions gained from the field study as well as the questions still open are summarized in Chap. 5. The devices do show promise as being effective for continuously monitoring the local scour around a bridge pier. The long-term survivability of the monitors in the Indiana stream environment, where woody debris is prevalent with no countermeasures taken, remains still to be proven. 


\section{Chapter 1: Introduction and Scope}

\subsection{Local scour around bridge piers}

Bridges of any significant span constructed over streams require the support of piers. The latter may then be subject to the erosive action of the water flow on the erodible streambed material. A general discussion of local scour around bridge piers may be found in Richardson et al. (1990, 1991) as well as in the first report of this project. The mechanics of local scour is extremely complicated, involving an unsteady fully three-dimensional turbulent flow strongly interacting with an erodible bed. While much qualitative and, to a more limited extent, quantitative can be learned from laboratory studies of the kind undertaken in the first part of this project, the need for field studies remains unquestioned. In addition to questions of scaling, the geometric complexity of a cross-section in the field and its attendant effects of the flow are difficult to reproduce faithfully in the laboratory. In the present project, the aim of which is the examination of the effectiveness of scour-monitoring devices to be deployed in the field, practical difficulties due to the presence of vegetative debris may arise in the field and have substantial implications, but which might be considered extraneous to the fundamental problem of local scour.

Because local scour may eventually lead to catastrophic failure of a bridge, with potentially considerable direct and indirect costs, bridge inspection, undertaken at periodic intervals, usually include a pier scour component, possibly involving underwater investigation. These are typically performed at low water surface levels, when the risks of injury to the bridge inspection personnel are minimal. The results of such inspection may however be quite deceptive. Pier scour may be a very dynamic phenomenon, in which the scour hole attains its maximum depth at or near the maximum flood stage, but is gradually filled in as the flood recedes. There may thus be little indication of the maximum scour that has occurred at a site when a bridge is being inspected at low water, yet it is the maximum scour that is of concern when evaluating the need for remedial measures.

In order to overcome the limitations of periodic bridge inspections with respect to pier scour, automated devices that are able to monitor continuously (without human intervention) the growth of a scour hole have been developed with funding from the FHWA and NCHRP. Further, because these devices are accepted by these agencies as valid scour countermeasures, they may prove to be useful tools in a more comprehensive bridge management/maintenance plan, providing added flexibility in decision-making and establishing priorities regarding scheduling of remedial or rehabilitation work. Two devices in particular have received the bulk of the attention, one based on a magnetic collar which can slide down a steel rod driven into the stream bed, and the other based on acoustic (sonar) sounding of the bed. The present work investigates the practical problems that may be encountered in the deployment of these two devices, and their general promise for streams in Indiana, and more generally in the Midwest.

In this report, a description of these devices is first given, together with an outline of the principles of their operation. Although much of this material can be found in a series of NCHRP reports (Lagasse et al., 1997; Schall et al., 1997a, 1997b), interest will be focussed on the device 
configuration actually deployed during the field tests. The installation and routine operation of the devices are discussed, again emphasizing problems encountered during the present study. A sample of the data so far obtained is presented, providing a context to evaluate the performance of the devices, in terms of their consistency with each other and their consistency with hydrologic data collected during the same period. 


\section{Chapter 2: The scour monitoring devices}

The main aim of the present project was the study of the effectiveness of two fixed scourmonitoring devices, one based on the sliding magnetic collar, and the other based on a sonar fathometer (fishfinder). In this chapter, background is provided on the choice of these devices, together with a description of the devices and their principles of operation. Much of this material is taken from a series of NCHRP documents (Lagasse et al., 1997; Schall et al., 1997a,b), which report on NCHRP Project 21-3.

\subsection{Background: NCHRP Project 21-3 and its conclusions}

Continuous monitoring of local scour around bridge piers may serve both as an early-warning system for indicating dangerous or scour-critical situations, as well as an information tool to aid decision-making regarding the necessity for and the scheduling of remedial measures. As such, the National Cooperative Highway Research Program sponsored Project 21-3 to evaluate various scour-monitoring technologies, and then to further develop and test the most promising of these in the laboratory and in the field. The work was performed by Ayres Associates, Fort Collins, Colorado, with support from various other public and private bodies.

The primary criteria to be satisfied by the devices were that i) these could be installed on a bridge pier or abutment, ii) these could measure the maximum depth of scour to within $0.3 \mathrm{~m}(1 \mathrm{ft})$, iii) the measurements could be read (taken) remotely or at least above the water, and iv) these could be operated under flood conditions. Additional desirable features would be low cost, ease of installation on existing as well as new bridges, and robust behavior over a wide range of flow conditions, including resistance to ice and debris.

Four broad classes of devices were considered in the project, i) mechanical sounding rods, ii) buried or driven rods, iii) sonar, and iv) other buried devices. Mechanical sounding rods, relying on a rod to touch the streambed, have been used for many years to measure the local depth, and so provides a simple means of determining scour. Although laboratory tests of a suitably refined model gave good results, experience in the field with a commercially available device (the Briscoe monitor) was disappointing, with repeated problems with automated measurements and the associated electronics. From the class of buried or driven rods, the device based on a sliding magnetic collar was deemed the most suitable, satisfying the primary criteria, and possessing most of the other desirable features. Similarly, the sonar fathometer was judged to meet the primary criteria, and considered the most promising for immediate deployment. Both of these devices will be described in greater detail below. Of the other devices studied, a promising option was a driven rod, somewhat similar to that used in a sliding magnetic collar device, but equipped with piezoelectric film sensors rather than a magnetic collar, with the advantage of not only recording the maximum scour depth but also capable of recording the subsequent infilling. It was determined however that additional research and development of such a device was necessary before any widespread field deployment was feasible. 
The major conclusion arrived at in NCHRP Project 21-3 was that two scour-monitoring systems satisfied the primary criteria specified, and had most of the desirable features. These were the magnetic sliding collar on a driven rod and a low-cost sonar fathometer, both of which subsequently underwent extensive field testing in various states, including Colorado, New Mexico, Texas, New York and Oregon, with generally positive results. Both of these devices were therefore chosen to be considered in the present study. Both devices were supplied by ETI Instruments Systems Inc. of Fort Collins, Colorado, who worked closely with Ayres Associates in the development and testing of the devices.

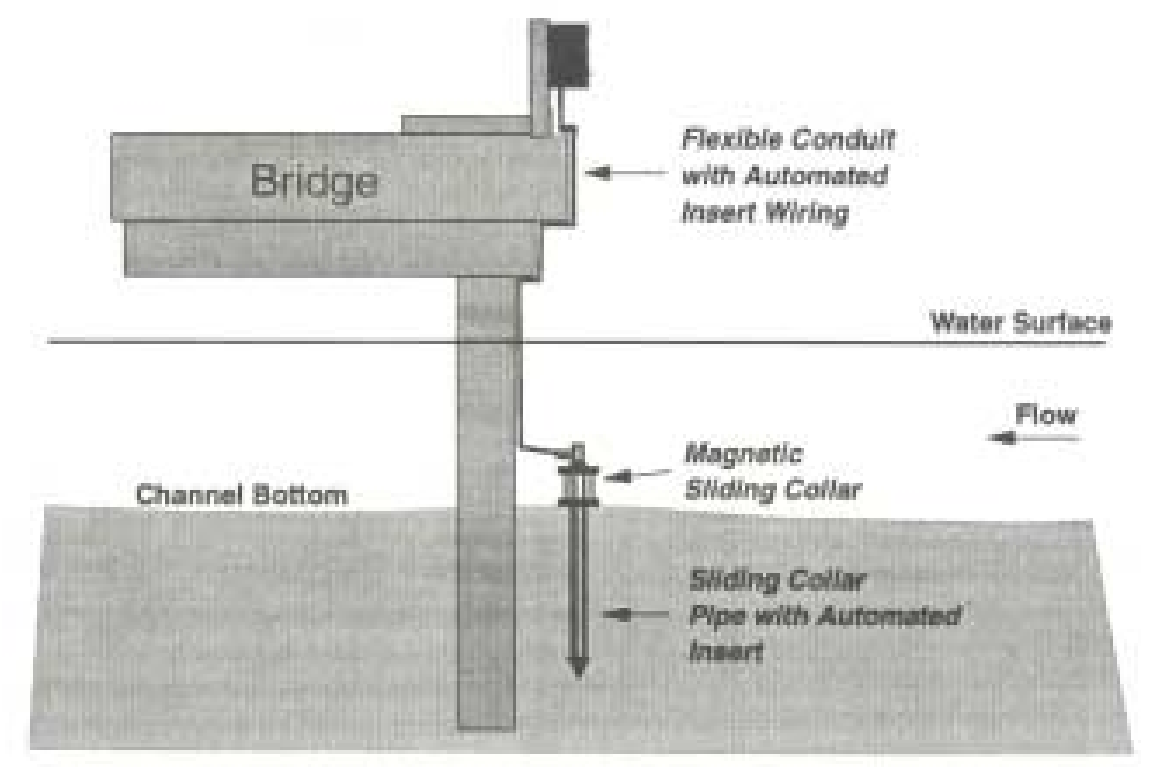

Fig. 2.1 Sketch of sliding magnetic-collar device with automated readout

\subsection{The Sliding Magnetic Collar device}

A sketch of the sliding magnetic collar device with automated readout is shown in Fig. 2.1. A 3$\mathrm{m}$ (10-ft) long Schedule 40 stainless steel pipe (see Fig. 2.2), 50-mm (2-in) in diameter, is driven into the streambed at a location where it is assumed or otherwise determined that the maximum scour will occur, typically in the vicinity of the upstream nose of the pier. A hardened driving point as well as a driving cap and provisions for the attachment of a driving pipe are intended to facilitate the driving process. On the rod is installed a magnetic collar, 165-mm (6.5-in) in diameter and 178-mm (7.0-in) high (see Fig. 2.3), which initially rests on the streambed, but which is capable of sliding freely along the rod. As the scour hole develops due to the flow around the bridge pier, the collar follows the streambed elevation by sliding along the rod. The location of the collar is determined by sensing the magnetic field of the collar by means of an array of resistors and magnetic switches (Fig. 2.4) placed at regular (152-mm or 6-in) intervals in a 12.5$\mathrm{mm}$ (0.5-in) diameter Schedule 40 PVC insert inside the rod. The wiring from the resistorswitch array is routed through a tee-fitting (Fig. 2.3) at the top of the steel pipe. As described in Schall et al. (1997a), the standard practice has then been to route the wire through a flexible conduit (Fig. 2.2) to an electronics box or enclosure on the bridge deck. In the actual installation 
for this project, this latter practice was originally followed, but then modified, as will be explained below.

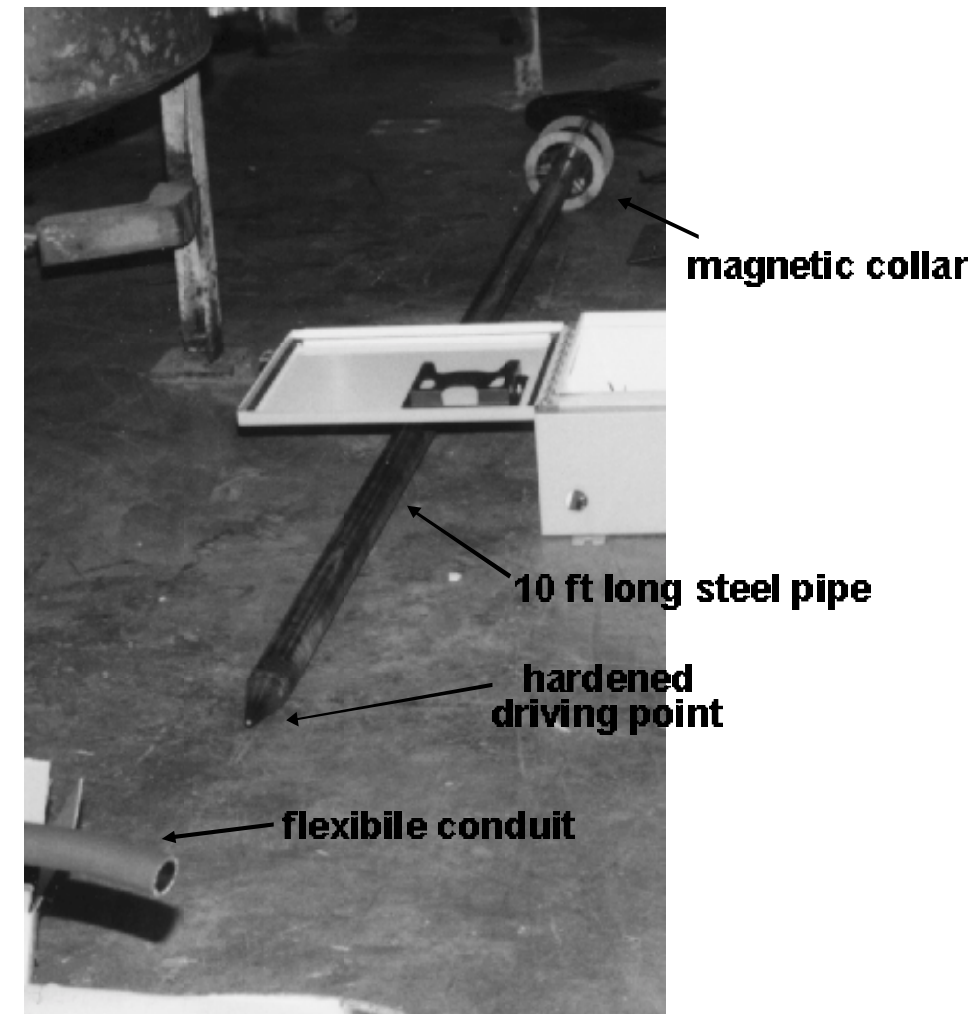

Fig. 2.2 Sliding magnetic collar on stainless steel pipe with driving point

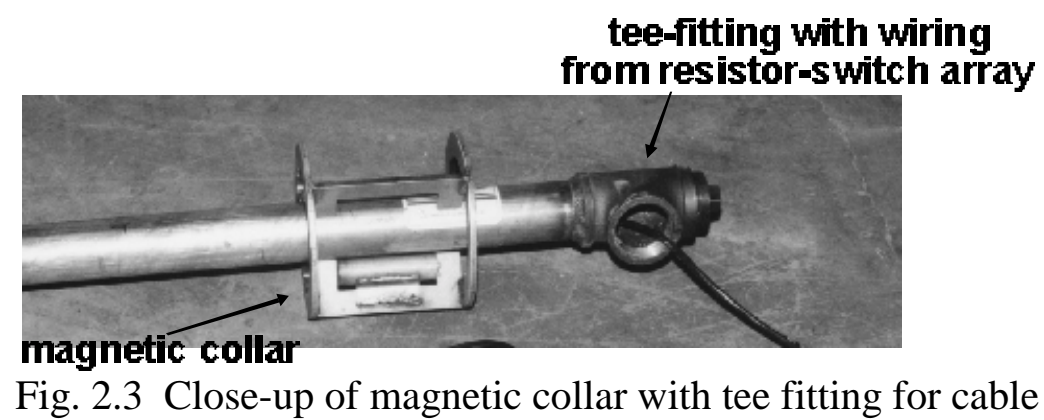

\subsection{The sonar fathometer}

A sketch of a mounted sonar fathometer that is above-water serviceable is shown in Fig. 2.6. A sonar transducer (see Fig. 2.7 for a close-up) emits a conical beam of sound waves, which is directed at the bed location where the maximum depth of scour is to be expected. In the model used in the present installation (Lowrance model no. 350A), the cone angle is $8^{\circ}$, operating at an emitting sound frequency of $200 \mathrm{kHz}$. This yields relatively good spatial resolution, even when installed in deeper (depth $>10 \mathrm{ft}$ or $3 \mathrm{~m}$ ) flows, because the beam is more concentrated and therefore 'sees' a smaller bottom region than would be the case if the cone angle were $20^{\circ}$, which is commonly found in recreational fishfinders. Sonar sounding technology in general is well established and tested, and is based on determining the time for a sound wave emitted from the 
transducer/receiver to travel to the channel bottom, to be reflected and received by the receiver. With the sound speed in water known, the distance to the bottom can be computed. Although the sound speed is affected by the density of water, and hence by factors such as temperature and turbidity, in the present application, the variations in density do not pose any serious problems for scour monitoring. The effects of entrained air bubbles and especially floating debris may however be much more substantial (Lagasse et al., 1997).

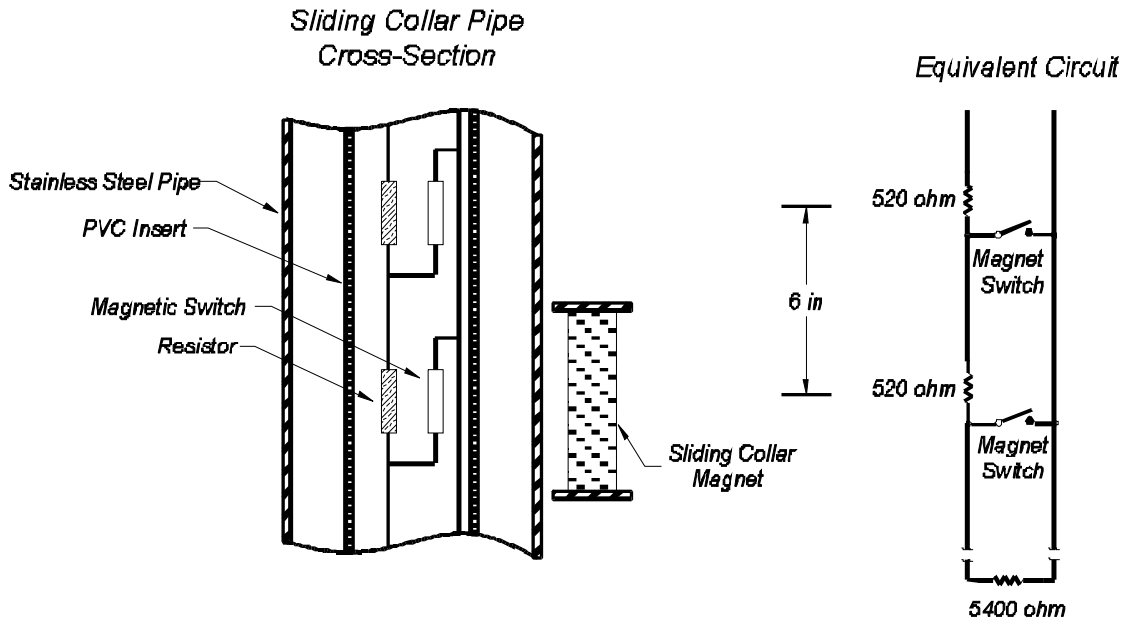

Fig. 2.4 Schematic of switch-resistor array inside of sliding magnetic-collar device

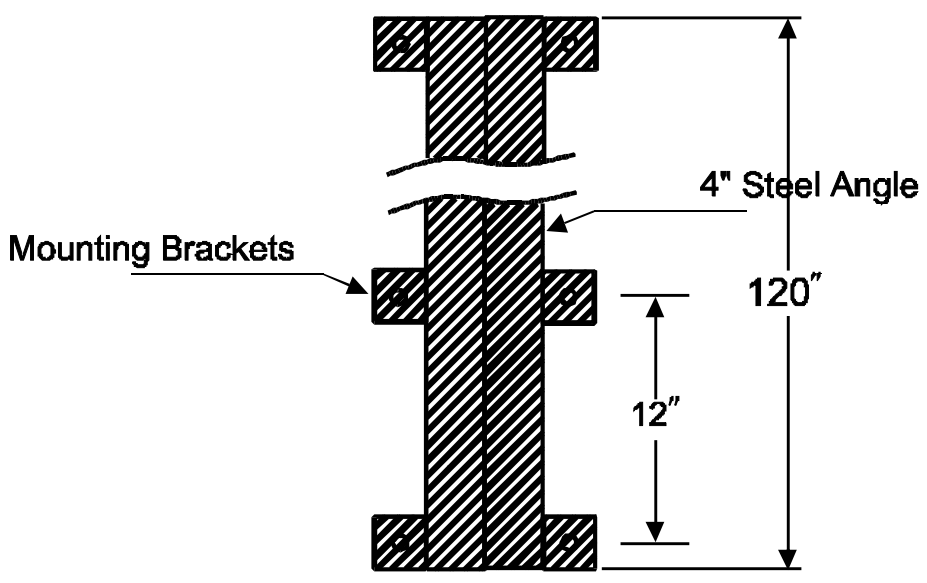

(a)

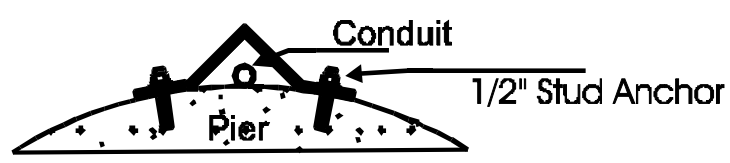

(b)

Fig. 2.5 a) Steel angle used for enhanced protection of cables from scour-monitoring devices, b) steel angle shown mounted to pier with $1 / 2$ " stud anchors 


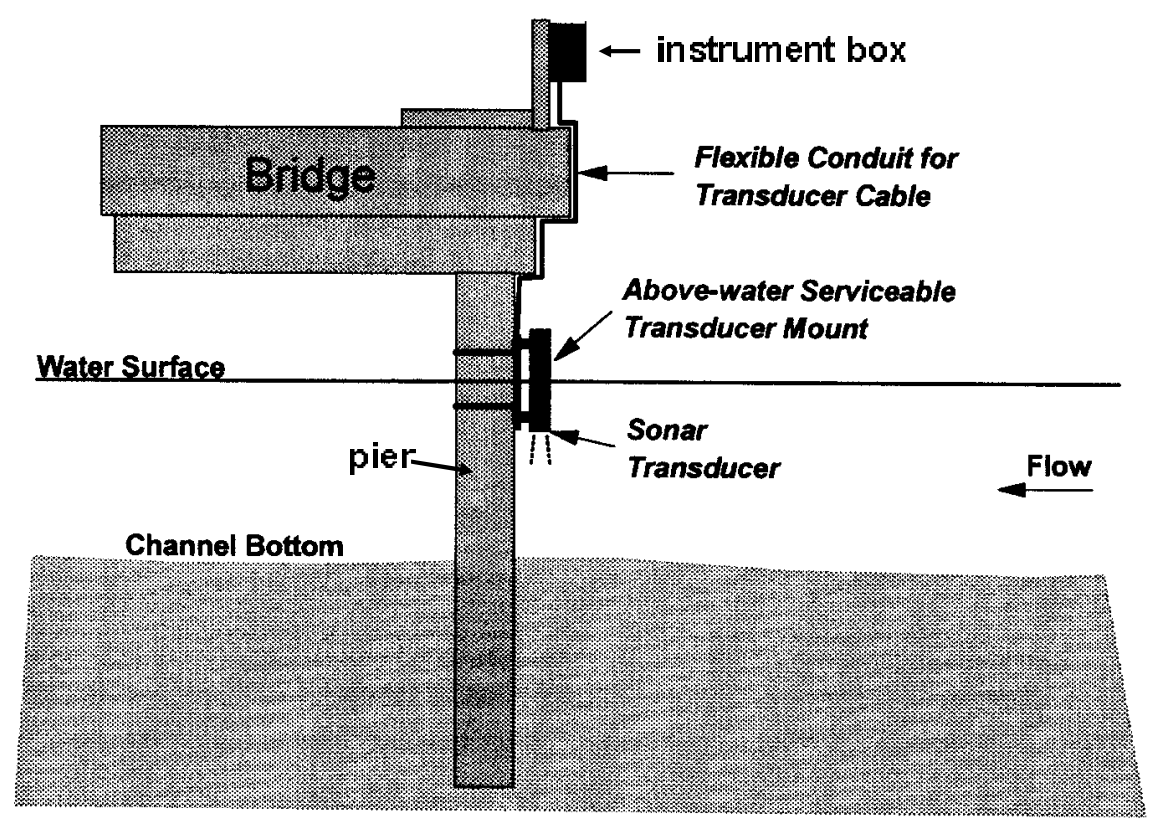

Fig. 2.6 Sketch of mounted sonar scour monitor

The 2-in (50-mm) diameter transducer is mounted by means of an all Schedule 40 PVC insert centered inside of a 4 -in $(100-\mathrm{mm})$ diameter steel pipe section. The mounting of the transducer in the PVC insert was angled outward to prevent the sonar beam from reflecting off the pier footings and was site specific (Wabash $12^{\circ}$, Wildcat $18^{\circ}$ ). In the original configuration, the 4-in steel pipe section was Schedule 40 (1/4" wall thickness), but in a later modified configuration, the pipe section was chosen to be a Schedule 80 (3/8" wall thickness). Mounting brackets, by means of which the entire transducer assembly could be bolted onto the bridge pier using stud anchors, were welded onto the pipe section. The transducer cable was routed via the insert, through a watertight conduit fitting, up the front of the pier in 1" heavy wall conduit.

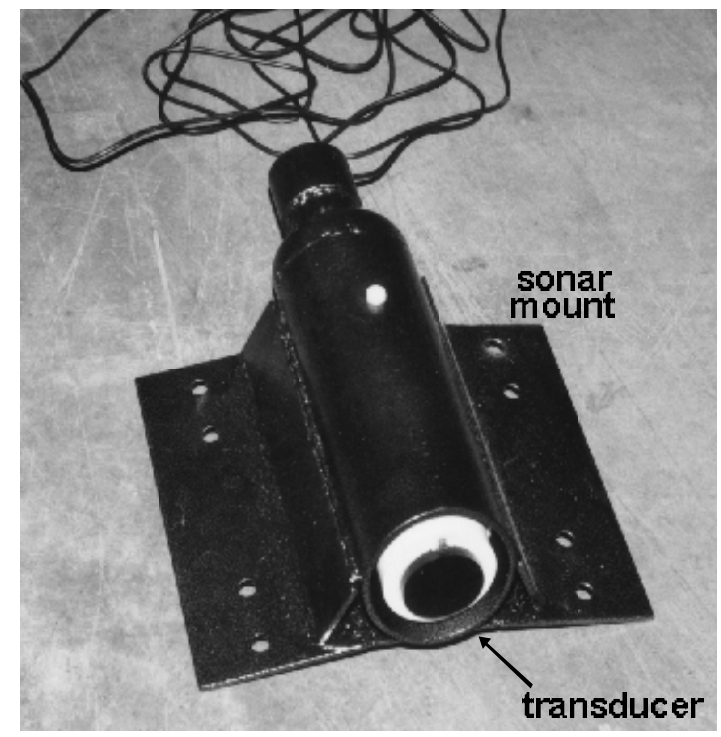

Fig. 2.7 Closeup of sonar unit 
A modification of the assembly was made in order to provide added protection from the impact of floating debris to the conduit containing the transducer cable. The initial modification consisted of covering the cable conduits for both the sliding collar and sonar with 4" $\mathrm{x} 4$ " $\mathrm{x} 3 / 8$ " thick steel angle 10ft long with welded mounting bracket every foot (Figs. 2.5, 2.8). These 10-ft sections were then installed over the existing conduit using 1/2" stud anchors.

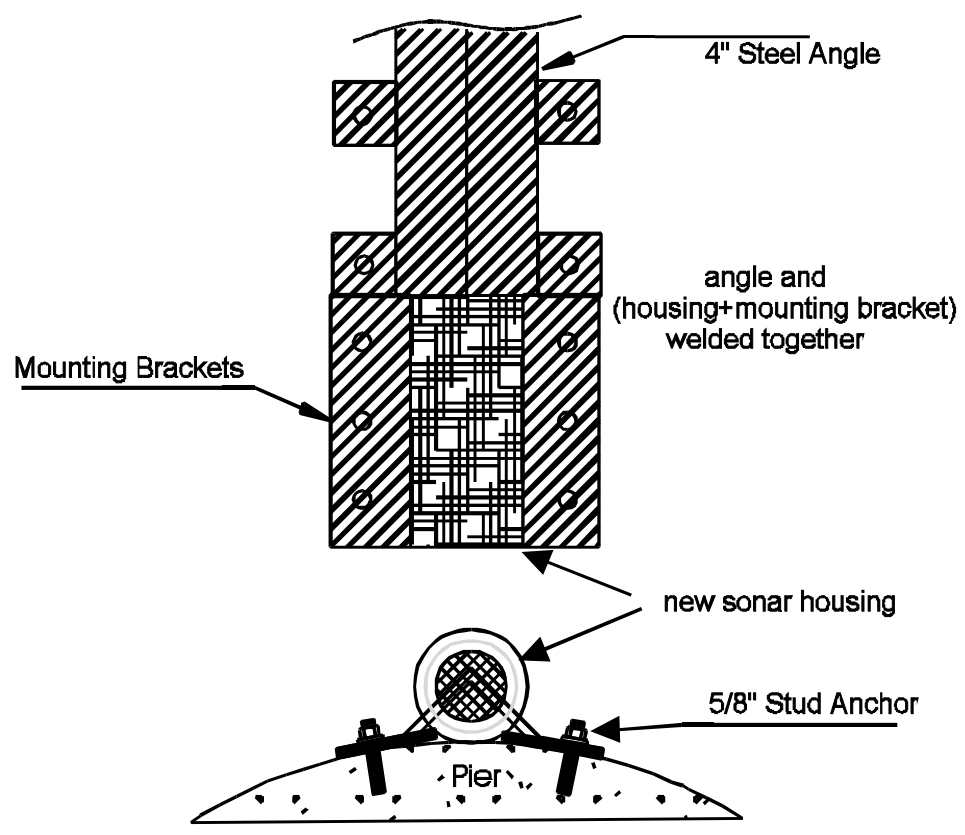

Fig. 2.8 Modified housing for sonar transceiver integrated into the steel angle

Later an additional modification was made to the Wabash sonar housing. This involved removing the lower $10-\mathrm{ft}$ section of steel angle protecting the conduit and welding a new sonar housing directly to the end of the steel angle (Fig. 2.8). The new sonar housing was constructed from 4" Schedule 80 steel pipe with mounting brackets welded along the side. Additional mounting brackets were also added to the steel angle every 6 inches. This entire assemblage was then reinstalled on the front of the bridge pier using 5/8" stud anchors.

\subsection{Electronics and instrument enclosure box}

In the present work, both the sliding magnetic collar device and the sonar fathometer device were to be studied, and so, contrary to what would be the case in practice, both devices were installed at each site at the same pier location. Cables from the magnetic switch array and the sonar transducer were routed to a single central instrument enclosure, which was a steel NEMA 12 enclosure, that was weatherproof and lockable, so as to discourage vandalism (Fig. 2.9). The enclosure contained the signal processor for the sonar fathometer (Lowrance, model LMS350A), a datalogger for unattended data acquisition and recording (Campbell Scientific, model CR10X), a relay for powering up the fathometer periodically when a reading was to be made, an interface provided by ETI Inc. for communication between the fathometer and the datalogger, a short-haul modem for communication with a laptop computer and a battery providing power for all the electronics. 


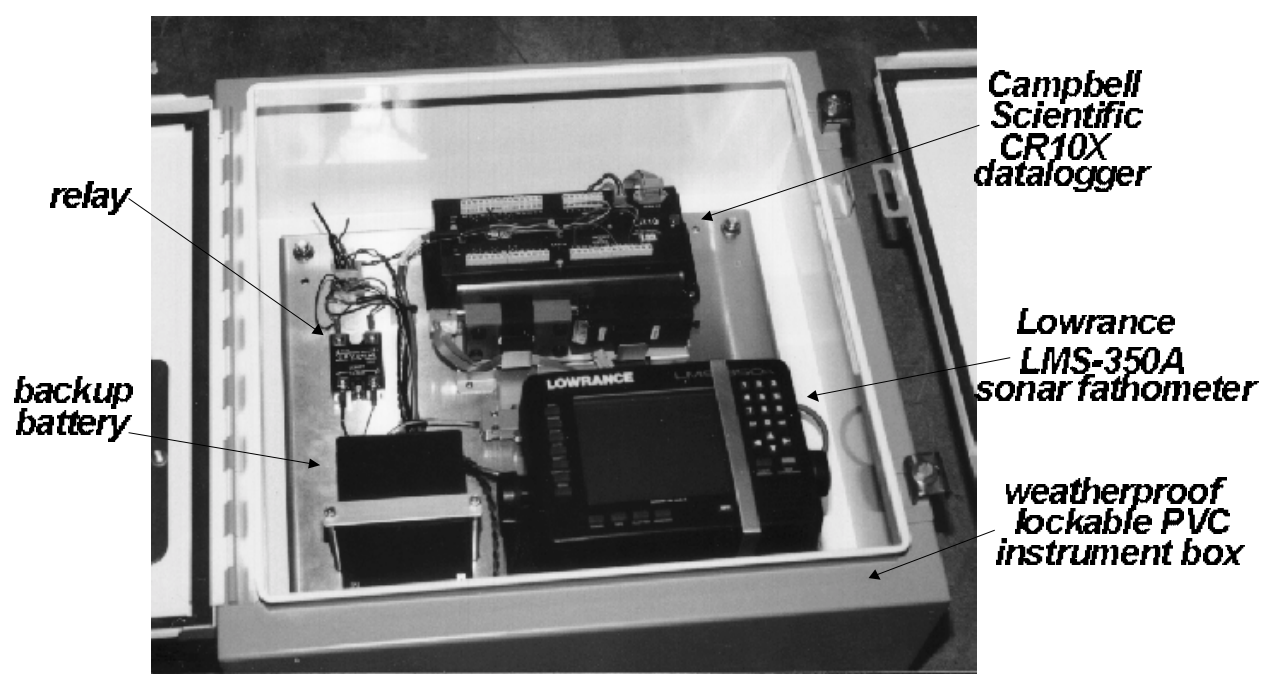

Fig. 2.9 Instrument box with sonar fathometer, datalogger, and battery

The instrument enclosure was mounted on the railing of the bridge deck (Fig. 2.10), with its cover away from the roadway in order to discourage vandalism. In addition, the enclosure could be locked. In order to facilitate maintenance of the instruments, however, the mount was designed with a hinge, such that the enclosure box could be tilted back and opened (Fig. 2.11). Two design choices deviated from the practice described in Schall et al. (1997a, b). Rather than relying solely on battery or a solar panel, power taken directly from the city lines was used to recharge the battery continually by means of a trickle charger. Further, because the bridges on which the devices were installed were heavily traveled, it was decided that downloading the data at a site other than the bridge decks would have significant safety advantages. Though telemetry or cellular phone connections were considered, it was decided that the use of short-haul modems would be more cost-effective for the present work. These allowed downloading the data using a portable (laptop) computer at a site close to (at the limit, less than 1 mile distant from), but not on the bridge deck. In comparison to remote telemetry, this solution was also advantageous in that the operator, who downloaded the data at weekly intervals, was also in a position to inspect the site for occurrences such as debris accumulation. A power line as well as a modem cable therefore lead from the instrument enclosure to a nearby pole, which was connected to a power line, and on which was installed a modem unit from which the data could be downloaded.

\subsection{Data acquisition using the Campbell Scientific CR10X}

ETI provides their own standard datalogger for the equipment configuration used, but offers the Campbell Scientific CR10X as an option. The latter was chosen since, unlike the former, it could handle the two separate inputs from the sliding magnetic collar and the sonar fathometer. In addition, the project personnel had good previous field experience with the CR10X as a very rugged and reliable fully programmable datalogger/controller with non-volatile memory and a battery-based clock. It can handle up to six differential or up to twelve single-ended analog inputs, and can be powered by any 12VDC source. Various devices can be powered up and controlled by the CR10X. It is fully programmable with 128 Kbytes EEPROM memory for the operating system and user programs, and 128 Kbytes SRAM for data storage which is backed up 
by a lithium battery. The computer program written to perform the data acquisition using the CRX10 is provided in Appendix 1.

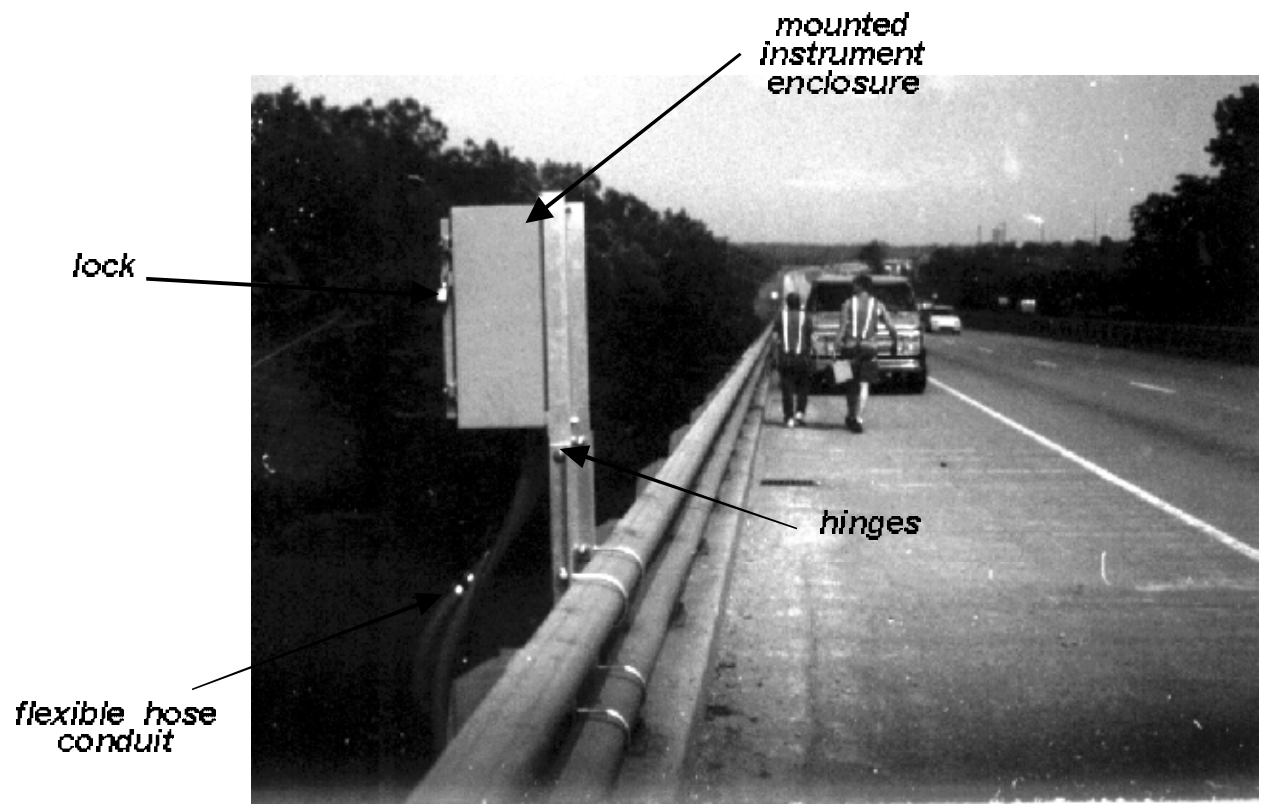

Fig. 2.10 Instrument enclosure on bridge deck (SR25 Wildcat Creek site)

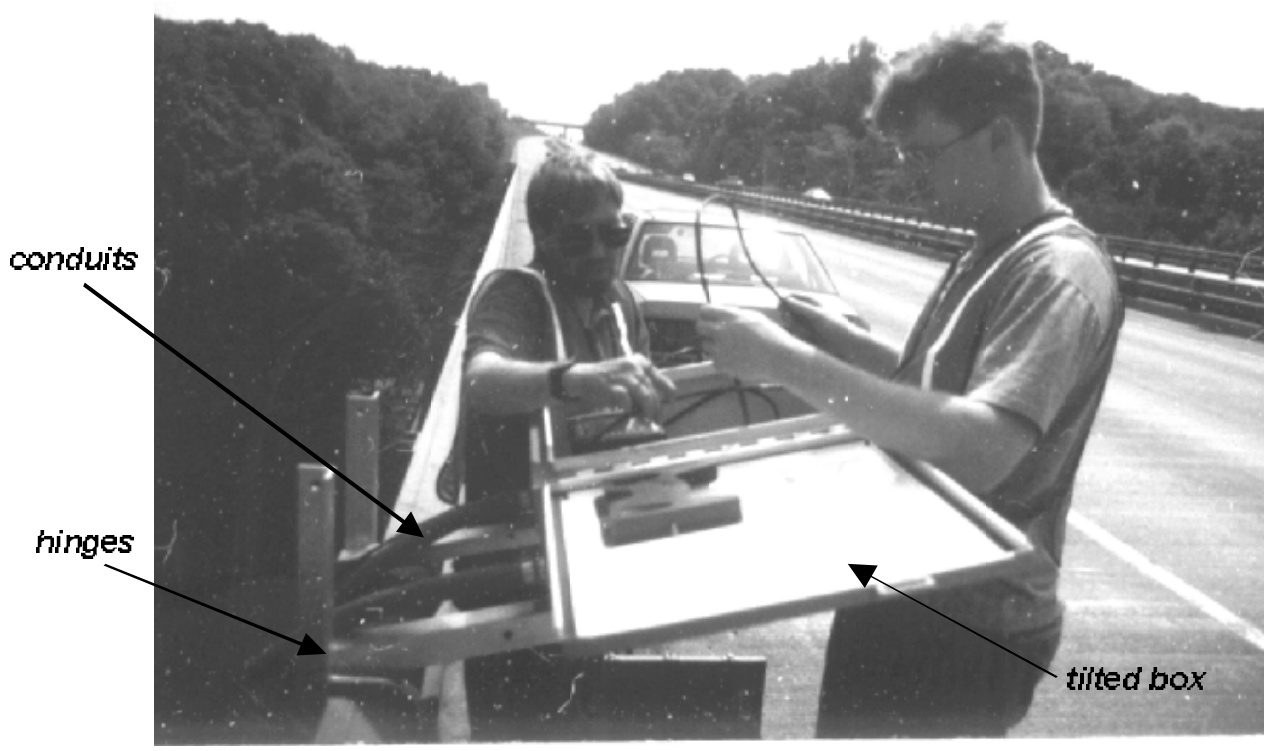

Fig. 2.11 Instrument enclosure tilted in its mount for working

\subsection{A portable sonar scour monitor}

A portable sonar fathometer (Fig. 2.12) was also acquired for use during the project. The fathometer is linked to a transducer that is attached to a float. The transducer/float can be positioned, e.g., by towing it with a boat to a location of interest, where it can be used to measure the depth of flow or locate the bed elevation. In this way, the bed level away from the pier where the fixed 
scour monitors have been or are going to be installed can be determined to provide a reference or initial level. Its use will however be typically restricted to low-water conditions because of safety considerations.

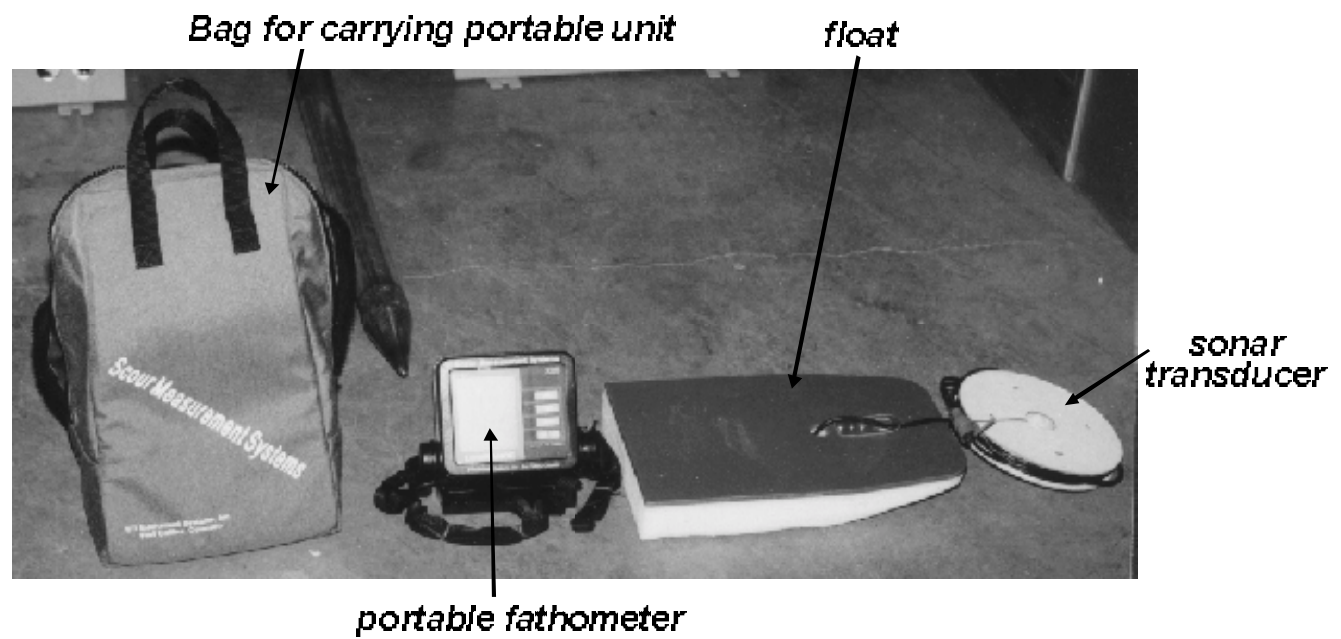

Fig. 2.12 Portable sonar fathometer system with float and carrying bag 


\section{Chapter 3: Installation and operation of the monitoring devices}

The proper operation of any device for field measurements requires its proper installation. In the case of scour monitoring devices, this involves working in the river environment which can cause special problems. In this chapter, the installation procedures, as recommended in Schall et al. (1997a, b), for both the sliding magnetic collar and the sonar devices are briefly summarized. Particular difficulties encountered during installation of the devices at the two sites will be mentioned. As part of a FHWA program promoting the deployment of these devices, Jim Schall of Ayres Associates was present for consultation during the initial installation of the devices at the US52 Wabash R. site.

\subsection{Installation of devices}

\subsubsection{The magnetic sliding collar device (with automated readout)}

According to Schall et al. (1997a), the recommended installation procedure begins with site preparation. Any debris at the selected pier where the device is to be installed should be removed. If the stainless steel pipe is to be driven, a exploratory test drive with an expendable rod or pipe should be performed to ascertain whether buried rock might cause any installation problems. For the sliding magnetic collar device with automated readout as in the present case, the stainless steel pipe with automated insert and tee-fitting, together with the hardened driving point if driving is to be performed at installation, should be assembled prior to being transported to the job site. It is also generally more convenient to complete all wiring to the instrumentenclosure box before arriving at the job site. As an added precaution, the correct operation of the automated insert should be checked before installation.

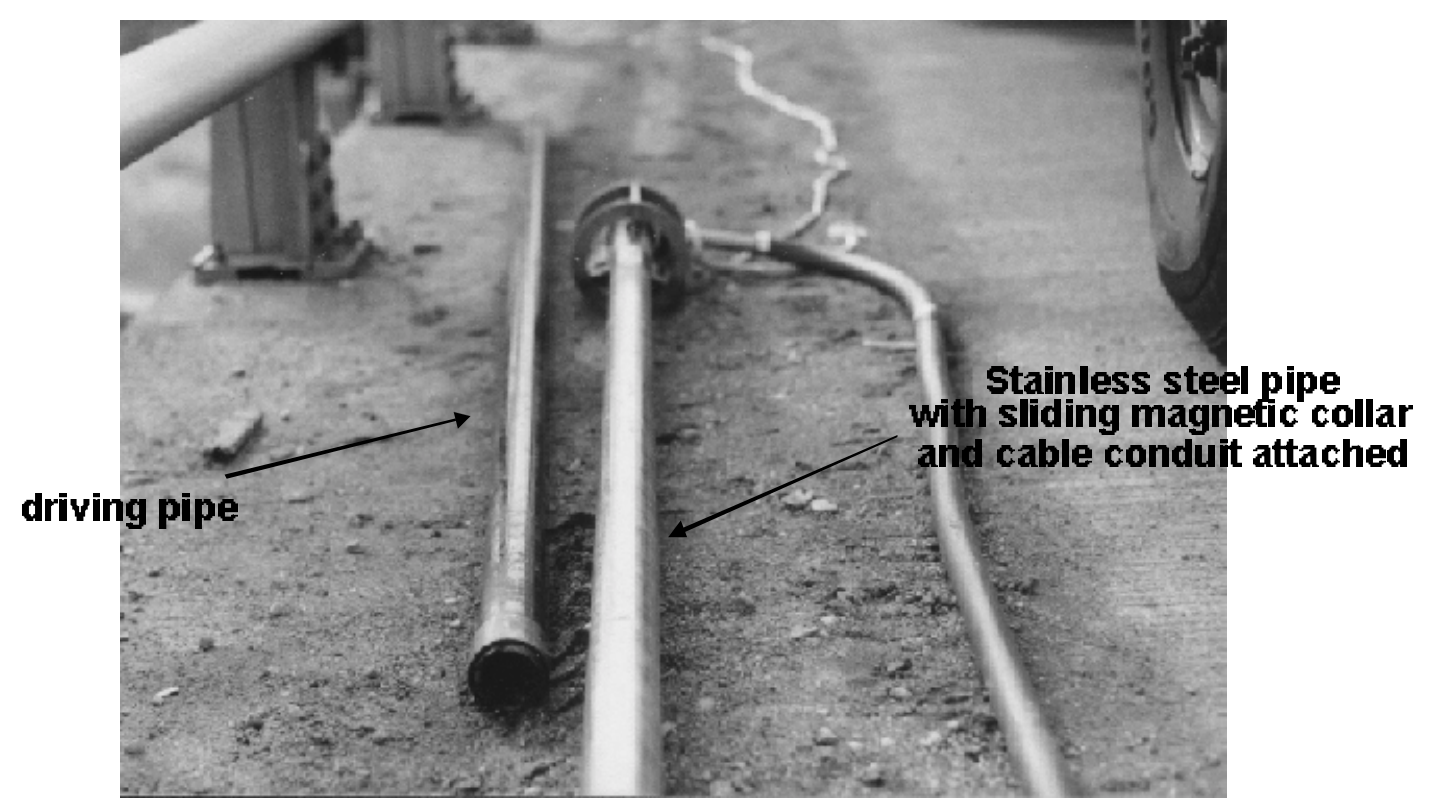

Fig. 3.1: Stainless steel pipe with collar and T-fitting in place beside the driving pipe 
At both sites, the stainless steel pipe was mechanically driven into the bed, and so a (10-ft or 20$\mathrm{ft}$ depending on the site) driving pipe (Figs. 3.1 - 3.2) was attached on top of the T-fitting by means of standard threaded fitting. It is important to be able to gage the progress of the driving in order to avoid driving the pipe too far with the result that the collar becomes jammed against or otherwise damaged by the T-fitting. For this reason, it is useful to mark the driving pipe at various locations (Fig. 3.3) so as to be able to determine approximately the location of the collar during the driving process.

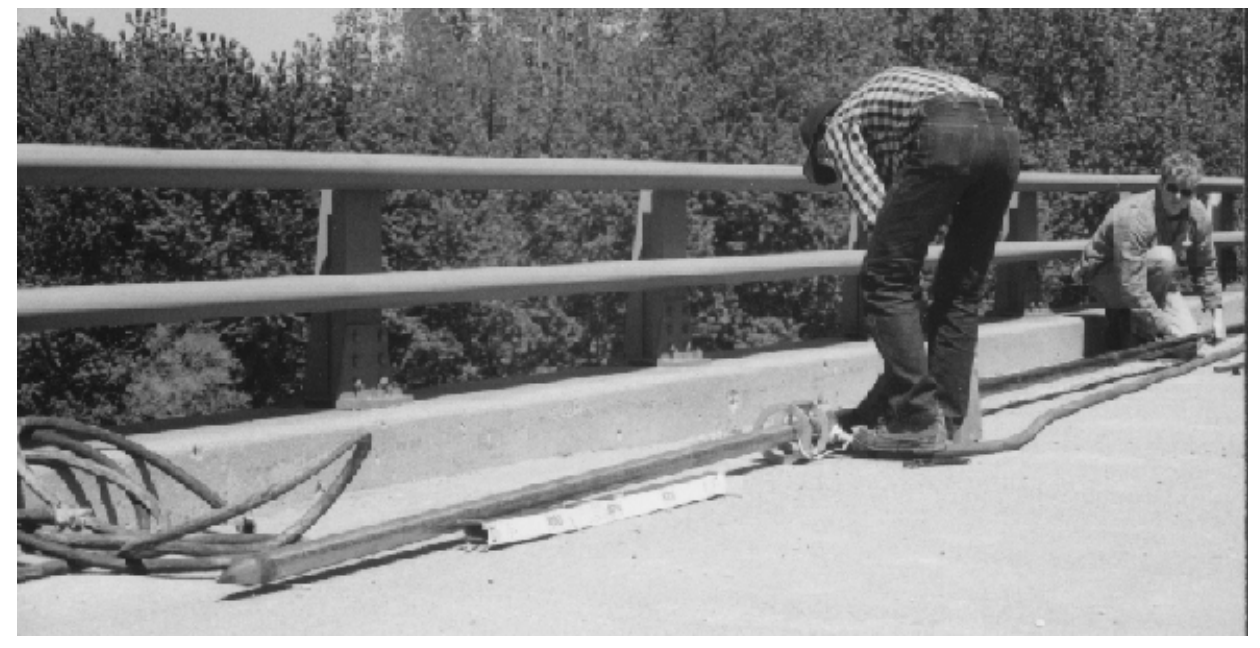

Fig. 3.2 Attaching the driving pipe to the stainless steel pipe

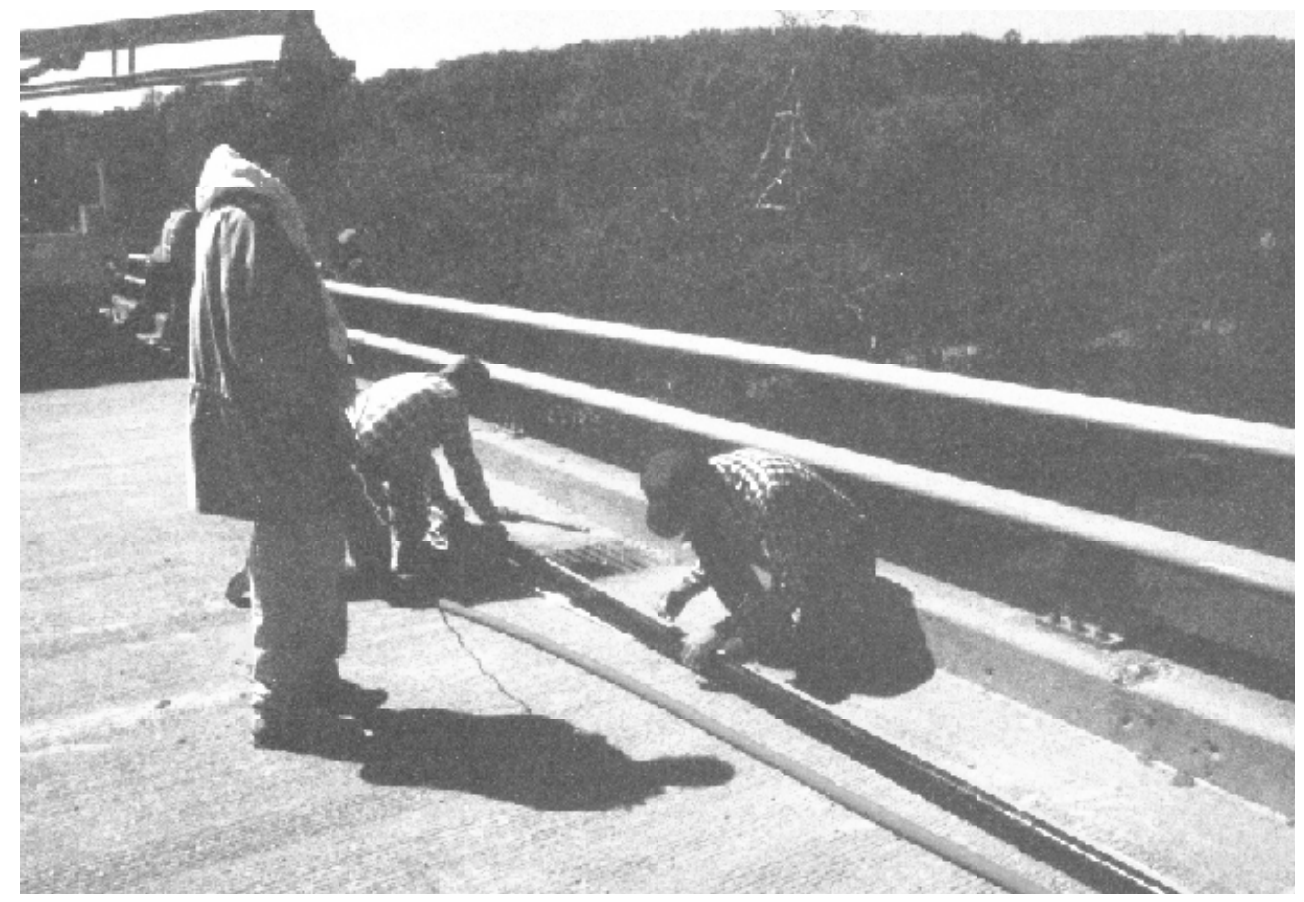

Fig. 3.3 Marking the driving pipe in order to be able to gage the progress of the driving and the location of the collar 
Because, for the device with automated readout, the sliding collar must be in position on the stainless steel pipe prior to being driven into the bed, it must be supported as the stainless steel pipe-driving pipe assembly is being positioned at the chosen site. This can be achieved by means of a rope threaded through the collar (Fig. 3.4). Depending on specific site conditions, such as depth of flow and distance of the water surface from the bridge deck, it may be helpful during the positioning and the driving process to also support the entire stainless steel pipe driving pipe assembly by ropes.

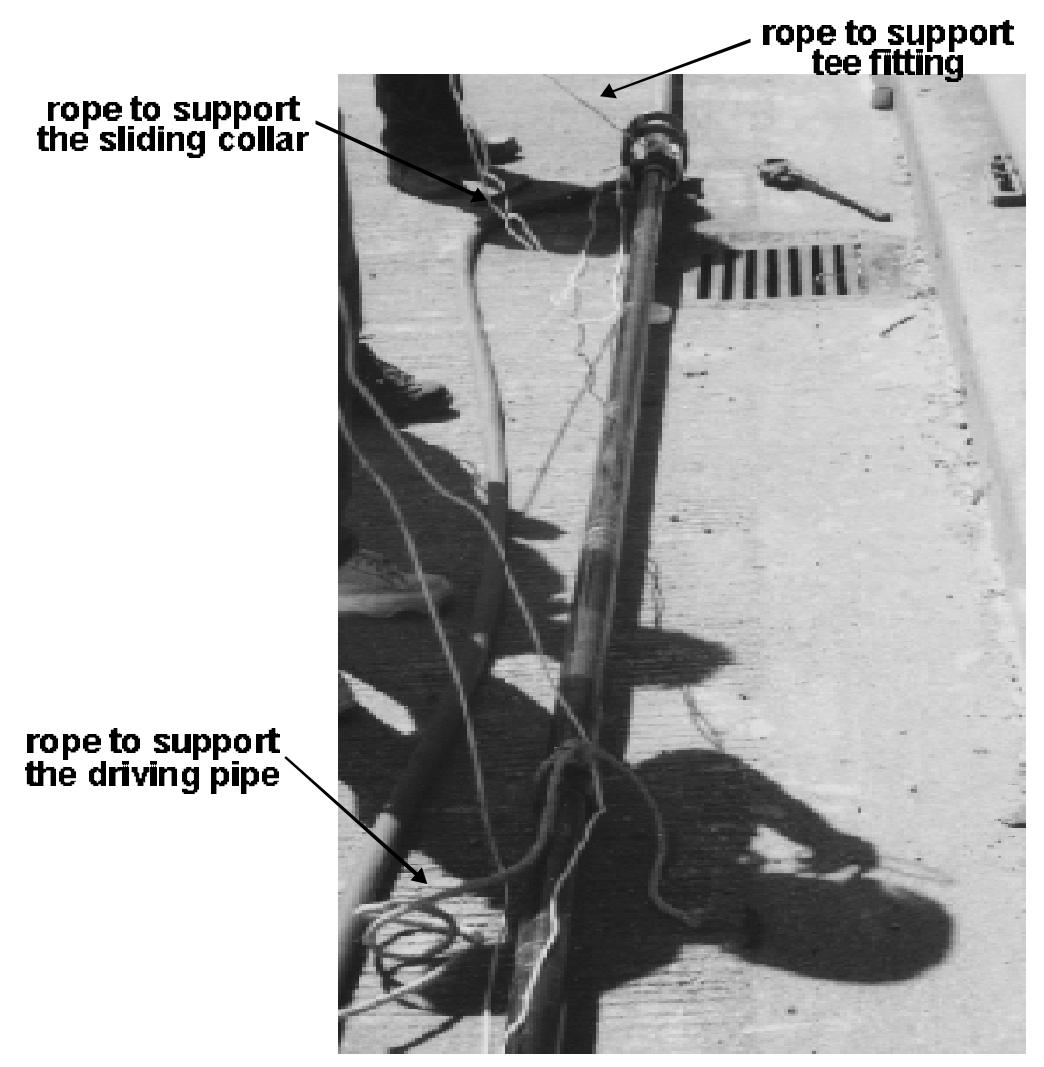

Fig. 3.4 The stainless steel pipe - driving pipe assembly with various supporting ropes

The assembly is then lowered over the side of the bridge (Fig. 3.5) to the water surface, with the help of a REACH-ALL and boat if necessary, and positioned. The pneumatic driver is placed on the driving pipe, and the driving process is started. It is recommended that, once started, the driving should not be stopped until the collar is at or very near the streambed, because it may be difficult to restart the downward movement. The cable conduit from the tee-fitting is then routed up the bridge pier to the instrument enclosure box on the bridge deck.

\subsubsection{The sonar device}

The installation site is prepared in the same manner as with the sliding magnetic collar device, namely by removing all debris at the chosen pier. Unlike the sliding magnetic collar device which is installed below the water surface, the sonar is installed above the water surface, and hence care must be taken that possible debris below the water surface be removed. The portable sonar device may be useful in determining the presence of underwater debris at the site. Further, since the sonar can only operate when it is submerged, it is generally advantageous to perform 
installation at low water stage such as to maximize the period when the sonar is submerged and hence maximize the measurement period.

Because of its relative compactness compared to the sliding magnetic collar, the sonar requires less effort during installation. The sonar transducer in its mounting bracket can be attached directly to the pier, and as in the case of the sliding magnetic collar, the cable from the transducer to the instrument enclosure is routed up the pier through a conduit.

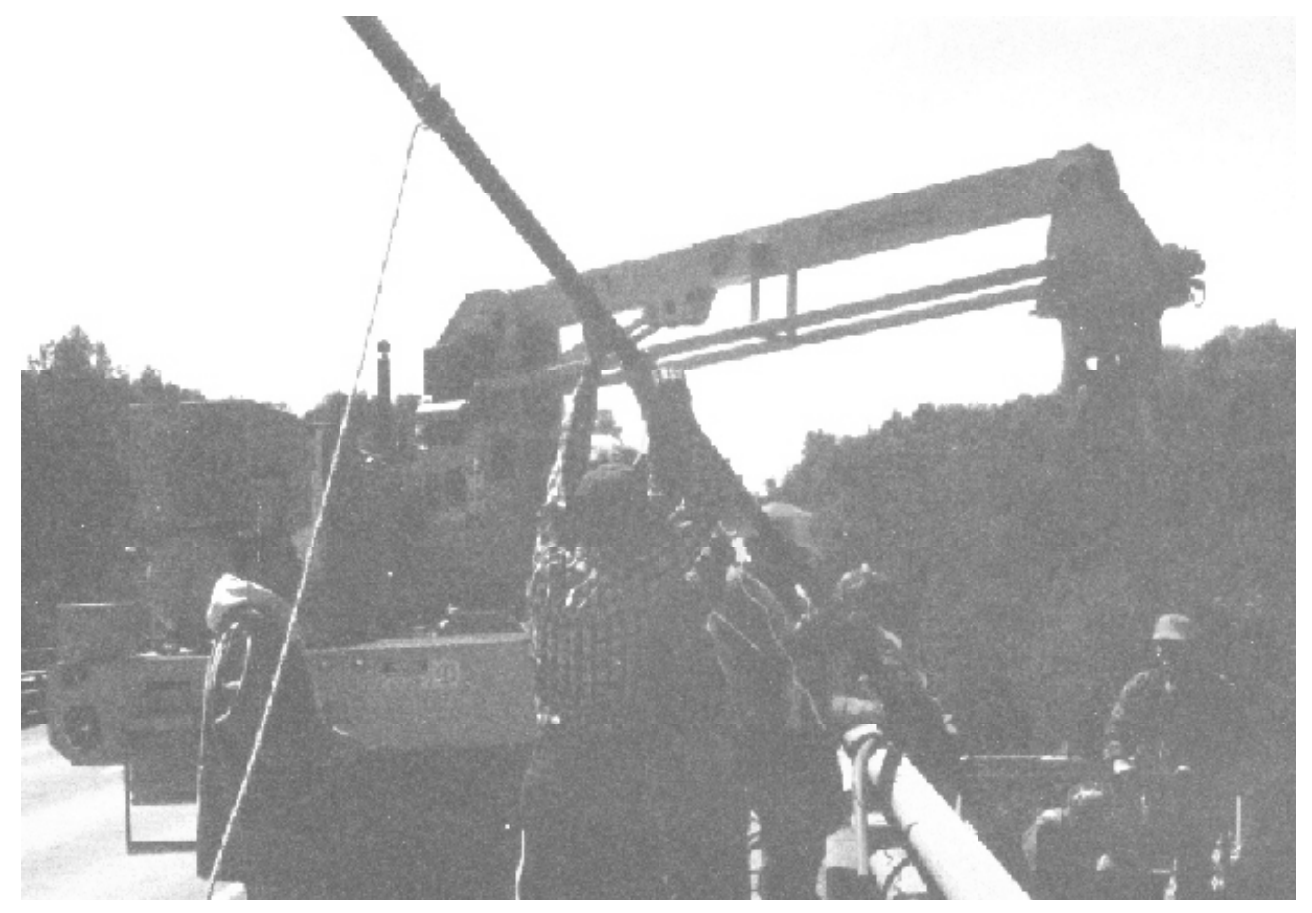

Fig. 3.5: Taking the stainless steel pipe - driving pipe assembly over the side of the bridge

\subsection{Special installation problems}

The above recommended procedures should apply to any site, and should be performed at all sites. Nevertheless, each installation site is different and each may present special site-specific problems that need to be dealt with. At the Wabash R. site, the main difficulty arose because of the distance of the bridge deck from the water surface. Even when fully extended, the REACHALL cab was still a significant distance from the water surface. Indeed, there was a gap of $\approx 3 \mathrm{ft}$ that was accessible to the installation personnel neither from the boat nor from the REACH-ALL $\mathrm{cab}$ (Fig. 3.6), which meant that part of the conduit through which the cables were routed up the pier could not be secured by stud anchors.

At both sites, the bridge deck is heavily traveled, such that downloading the stored data directly from the instrument enclosure on the bridge deck might present unnecessary hazards. It was therefore decided to locate the computer access at a more secure nearby location away from the bridge deck (Fig. 3.7). This necessitated the use of a short-haul modem, which was mounted on the pole providing power to the instrument enclosure. 


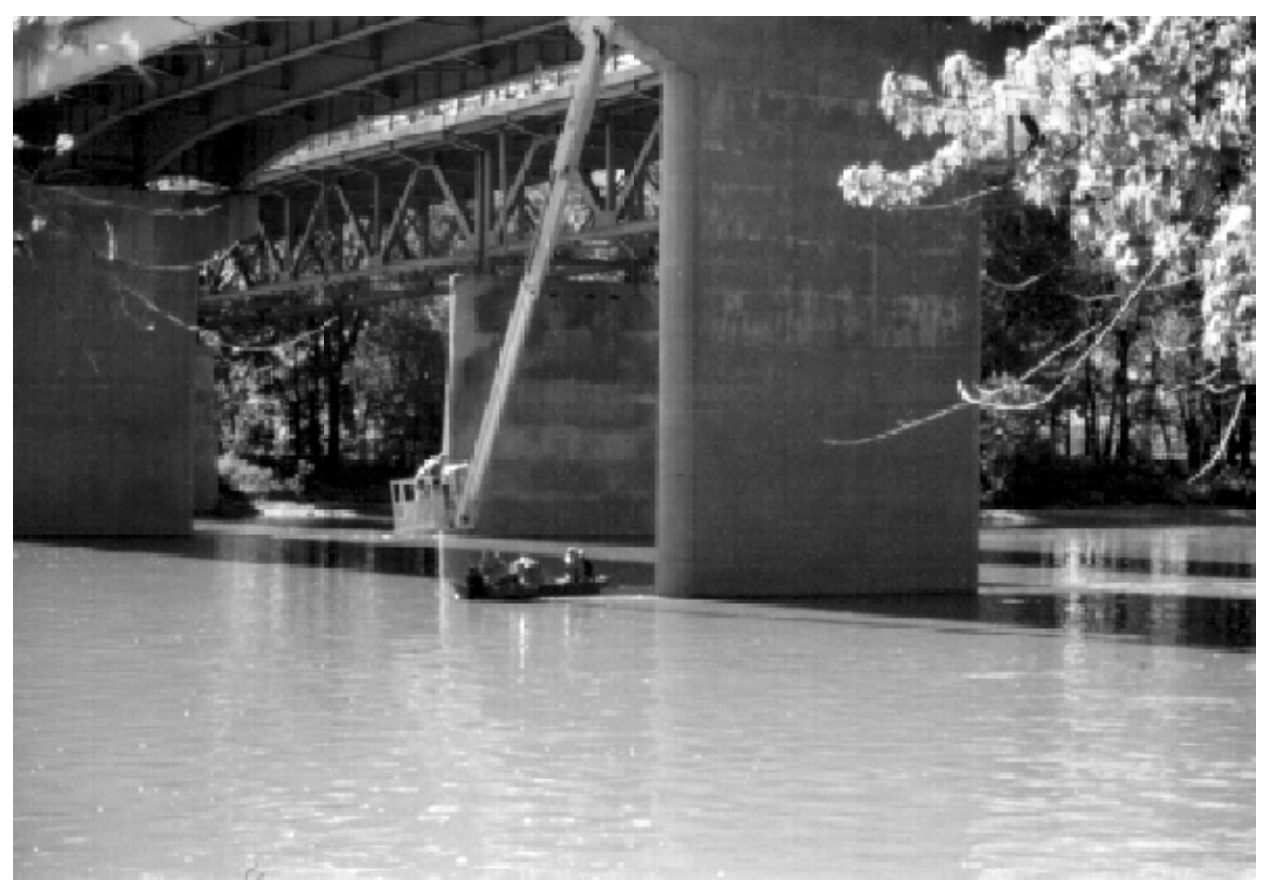

Fig. 3.6: Fully extended REACH-ALL cab and boat at the Wabash R. site

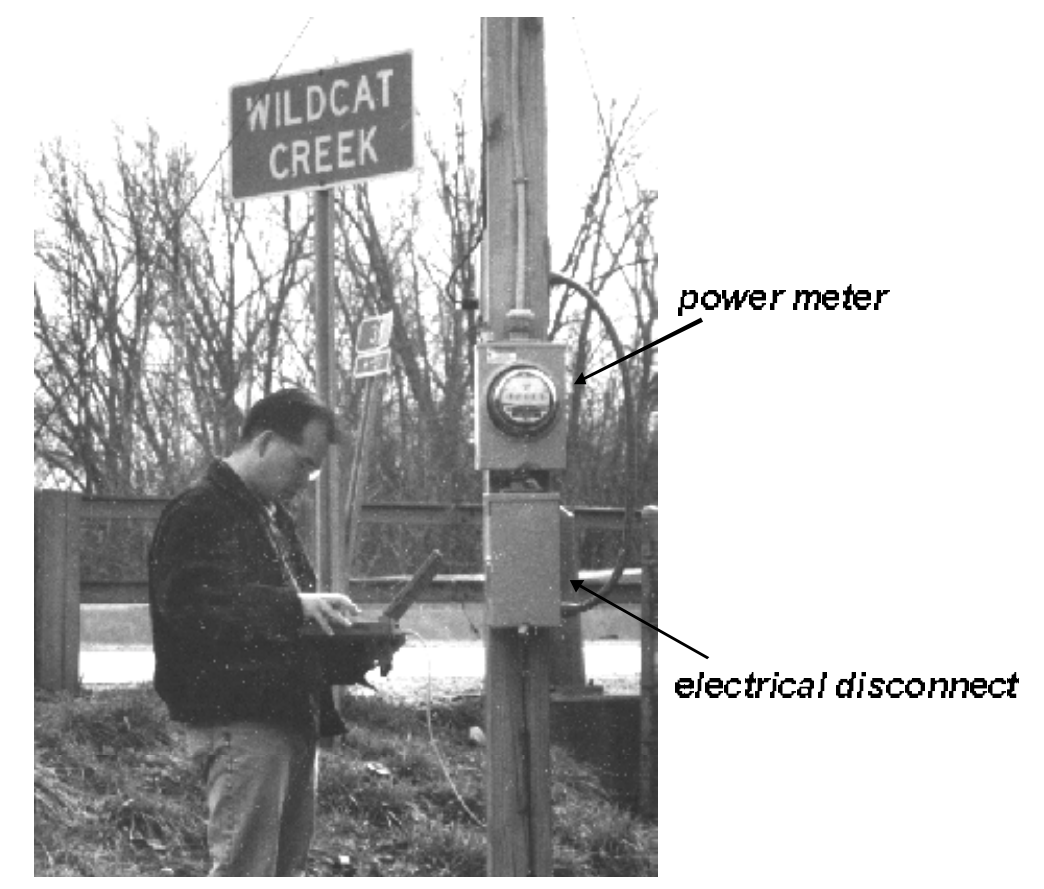

Fig. 3.7: Downloading the data from access point installed on power pole away from the bridge deck 


\subsection{Operation of the scour monitors}

Whether considered only within the context of the present project, or in a possible wider deployment of these devices, the scheduling of field installation, direct inspection, and major repairs of the scour-monitoring devices required both appropriate weather and flow conditions at a site as well as coordination with INDOT personnel and the availability of INDOT equipment. The devices were assembled, checked, and were ready and scheduled to be installed by Jan. 1997. High water levels and/or icy conditions as well as the extreme cold delayed installation until the late spring. Further, limited availability of installation equipment need to be considered in planning. In particular, the REACH-ALL was heavily in demand for other INDOT uses, especially during the summer construction season, and hence some delays in installation and maintenance occurred because of the limited availability of the REACH-ALL. As an example, it had been initially planned to install the scour-monitoring devices at both sites over a two-day period in May 1997 when the REACH-ALL was available. Because of unexpected installation problems at the US52 Wabash R. site, the installation could only be completed at this single site within the scheduled two-day period; as a consequence, the installation at the SR25 Wildcat Creek site had to be postponed until a much later date in November 1997.

One of the major issues under investigation in the project was the survivability of scourmonitoring devices subject to typical flood conditions in Indiana streams. During a flood event that occurred soon after the devices at the US52 Wabash R. site began operation, data acquisition from the sonar device stopped. An inspection carried out about two weeks later (when the river stage was sufficiently low as to permit observation of the sonar device) revealed that a 10-ft length of the original rigid galvanized steel conduit through which was routed the cable from the sonar and which was fixed to the nose of the pier by means of clamps had apparently been carried away by the flow. While the sonar transceiver was still sound, the cable was ruptured, thereby causing all communication from the sonar to the data recorder to be lost. Somewhat surprisingly, the flexible rubber hose through which the cable from the magnetic collar was still intact, though the clamps by means of which it was fixed to pier had been dislodged, and hence the rubber hose was flapping loosely in the flow. The sonar transceiver was dismounted and brought back to the laboratory for closer examination. In consultation with Prof. M. Bowman (Structures group, Purdue University Civil Eng.), a more robust alternative to the original rigid galvanized steel conduit for cable routing was developed, namely the steel angle described in the previous chapter.

In late January 1999, both devices at the US52 Wabash R. site as well as the magnetic collar device at the SR25 Wildcat Creek site were found to be not operating. Closer examination of the US52 Wabash R. site revealed that the cable from the magnetic-collar device was completely severed (Fig. 3.8), such that this device for scour-monitoring purposes is totally lost. The sonar transceiver, together with its casing and mount, at the same site had also been detached from the pier (Fig. 3.9) and apparently washed away. The pier with the cables, well protected within steel angles but severed from the scour-monitoring devices, and missing sonar is shown in Fig. 3.10. The damage is attributed to woody debris carried by the flooding stream, which either impact or become entangled with the pier, and hence the sonar transceiver or cable from the magneticcollar device. 


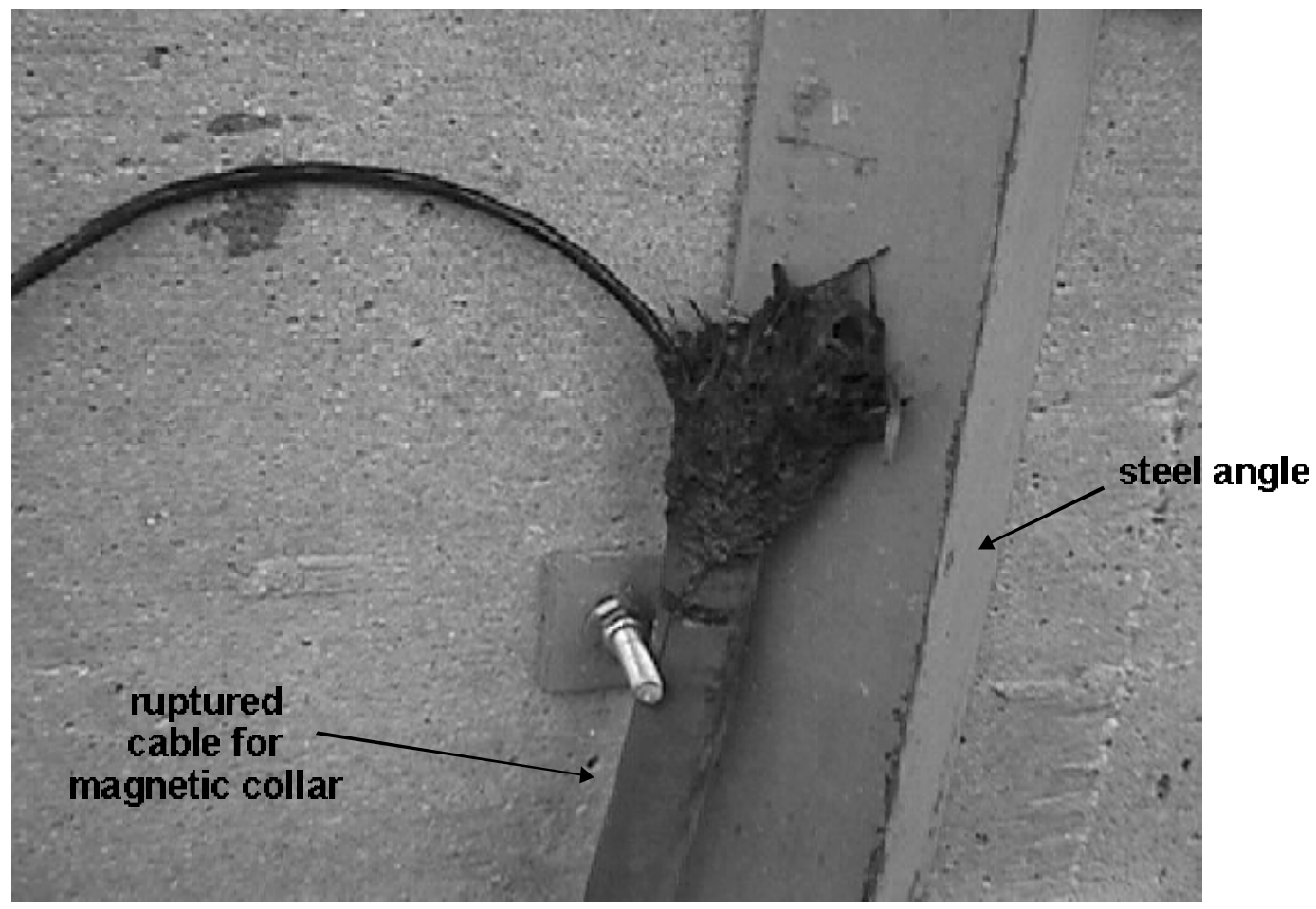

Fig. 3.8 Severed cable from sliding magnetic collar device at US52 Wabash R. site

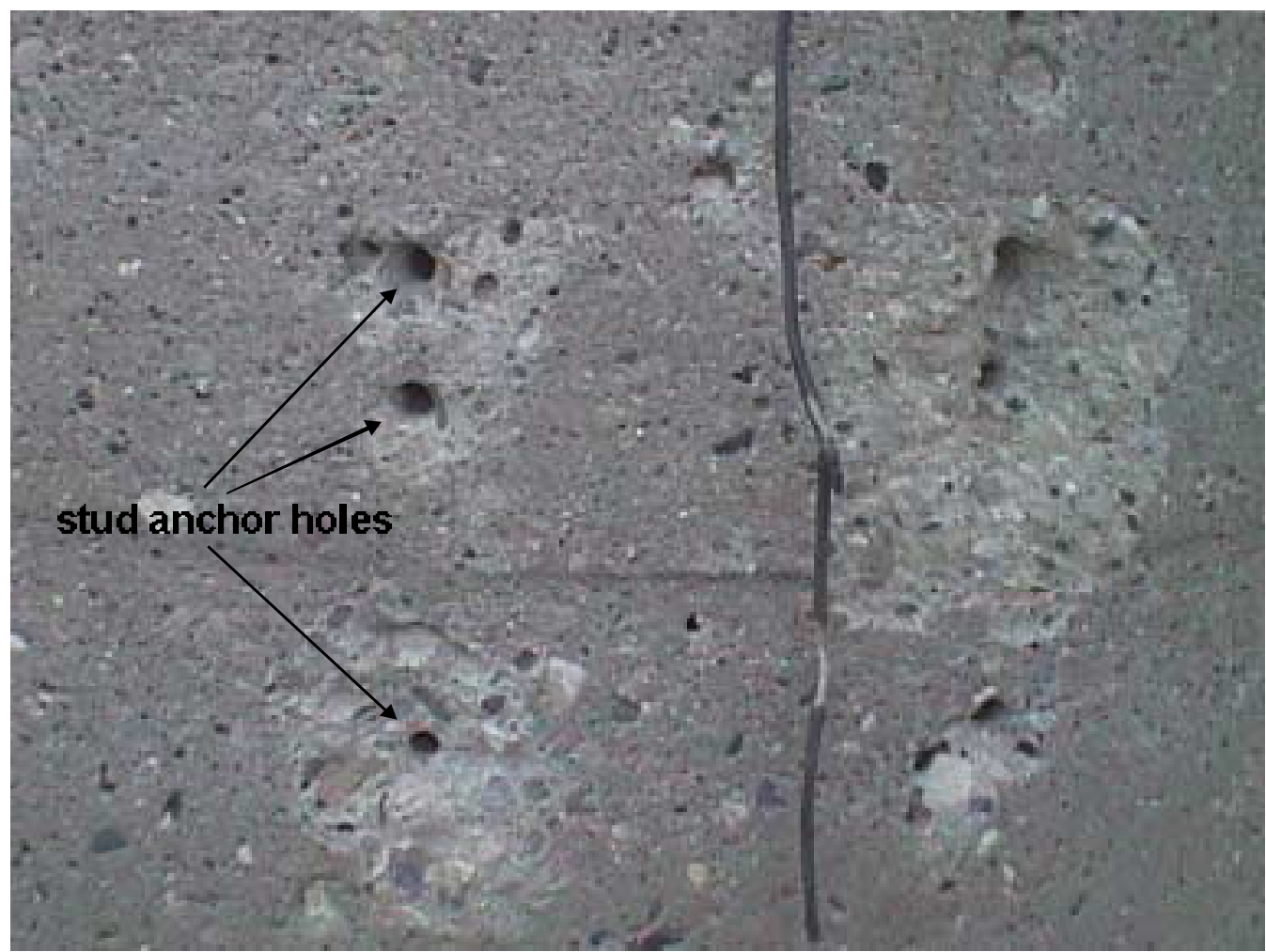

Fig. 3.9 Holes in pier at the US52 Wabash R. site that held the stud anchors attaching the sonar transceiver to the pier 


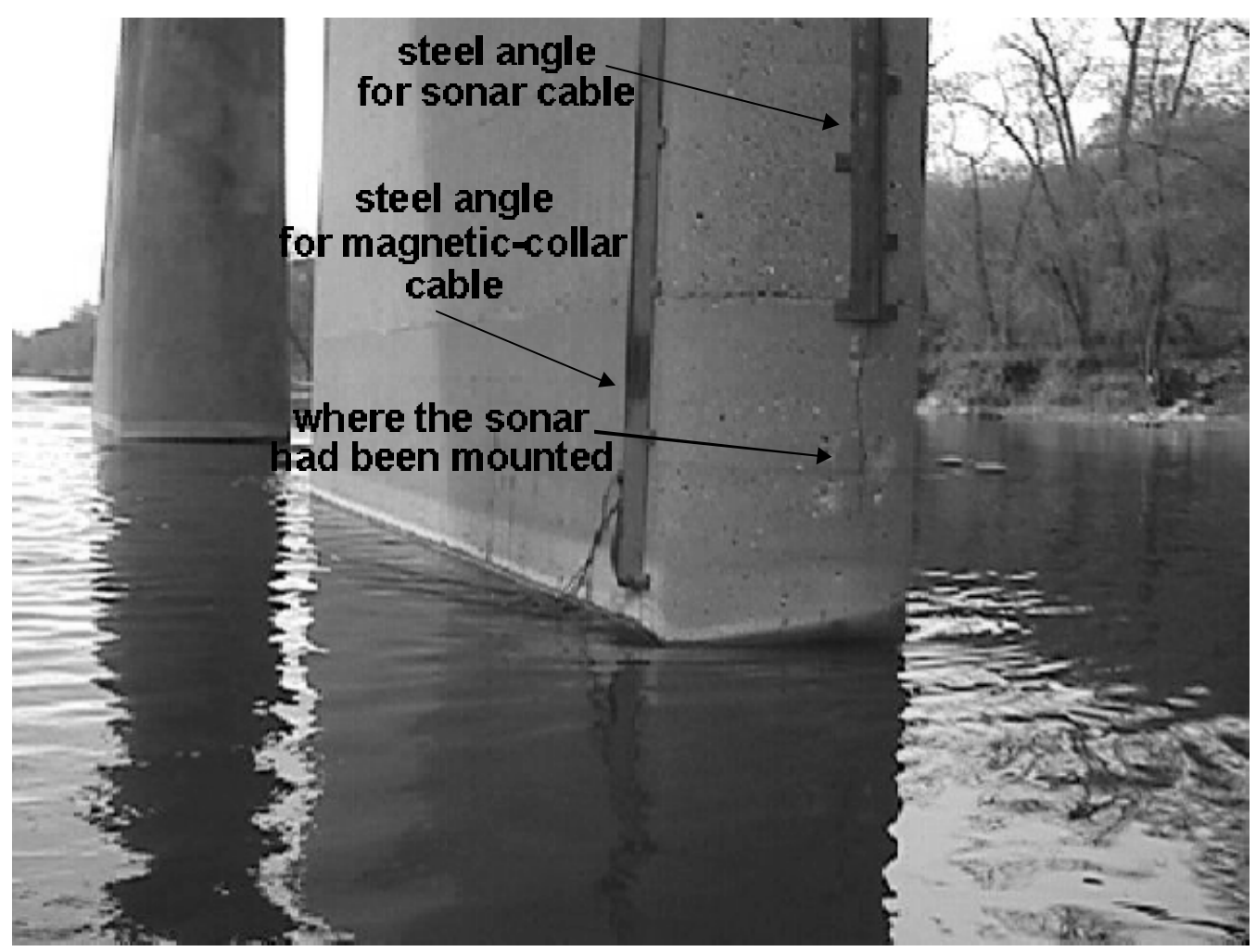

Fig. 3.10 The steel angles protecting the (severed) cables from the magnetic-collar device (on the left) and from the (missing) sonar transceiver at the US52 Wabash R. site

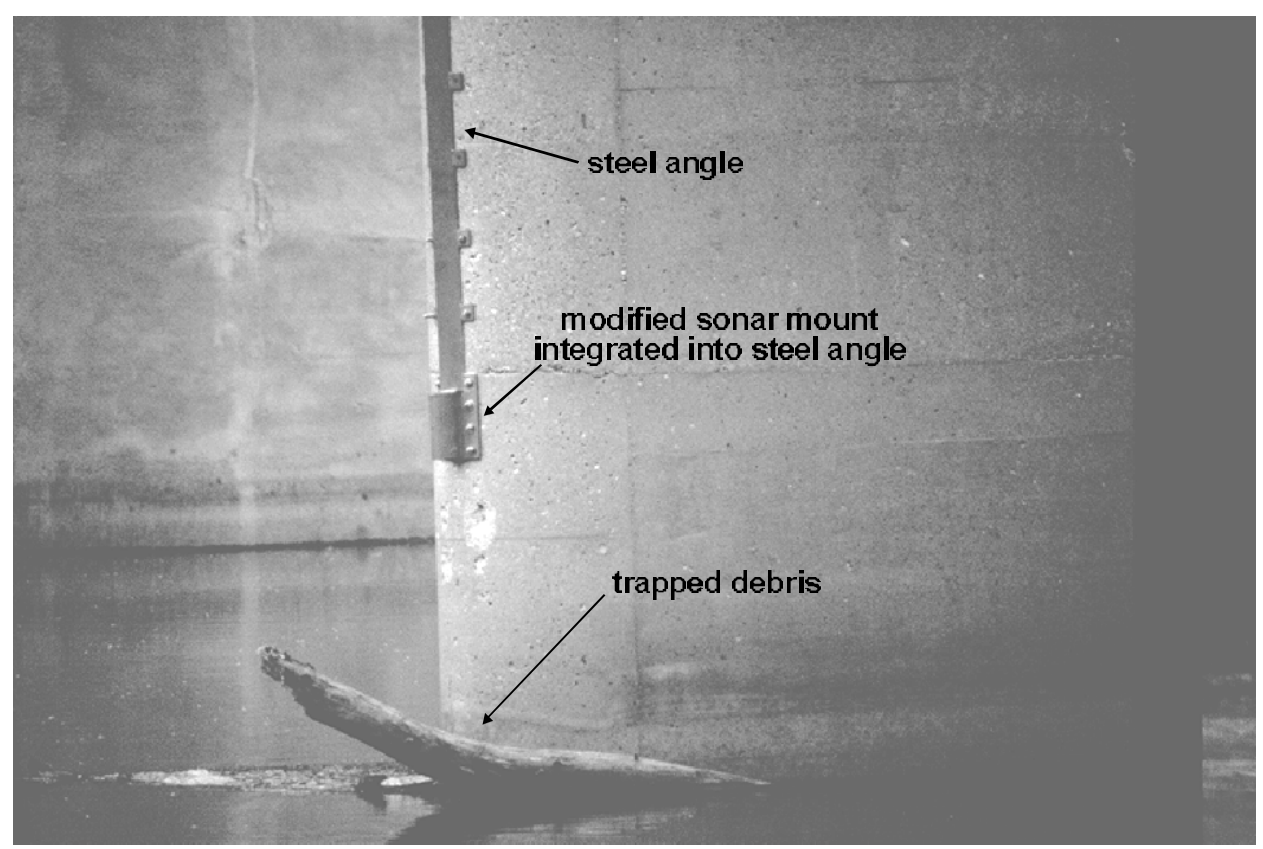

Fig. 3.11 Woody debris trapped at the US52 Wabash R. site on the pier with the sonar transceiver in its most recent version of the mount (integrated with the steel angle) 
Fig. 3.11 gives an example of woody debris being trapped at the instrumented pier at a later date when the sonar transceiver had been replaced with a modified version of the mount.

Debris also played the determining role in the damage caused (at approximately the same time and hence probably due to the same flood event) to the magnetic-collar device at the SR25 Wildcat Creek site. The debris pile-up at the instrumented pier is shown in Fig. 3.12. The sonar transducer is buried within the pile-up and has thus been rendered inoperable but was otherwise undamaged. On the other hand, the cable from the magnetic-

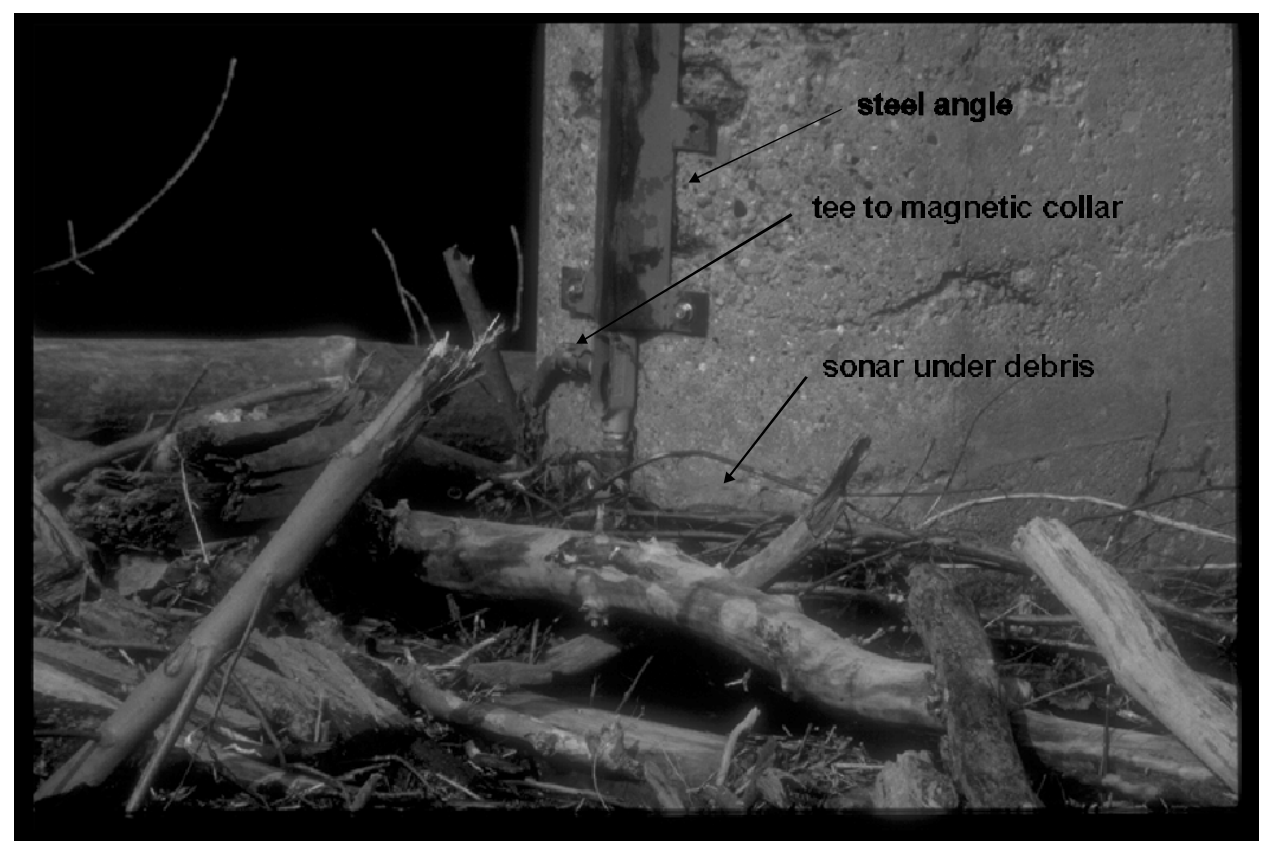

Fig. 3.12 Debris pile-up at the instrumented pier at the SR25 Wildcat Creek site (the sonar transducer is buried inside the pile-up)

collar device, in Fig. 3.12 merging into the protective steel angle through a tee, is seen more clearly in Fig. 3.13 as having its flexible (red) rubber hose being punctured and thereby presumably disrupting any signal transmission to the data recorder.

A new sonar transceiver was installed in the summer of 1999 at the US52 Wabash R. site with a modified mount that was integrated into the steel angle armoring the cable (see the previous chapter for details and also Fig. 3.11) to provide greater resistance against detachment. Since that time, no major flood event has occurred, and so it is not certain to what extent the modified mount will perform effectively in enhancing the survivability of the sonar transceiver. Similarly, at the SR25 Wildcat Creek site, the cable from the magnetic-collar device has been patched, though its long-term survivability at present is questionable.

Although damage to the installed equipment have been primarily due to natural events and directed against the sensors and the connecting cables, possible damage to the other components of the measurement system due to human intervention should not be overlooked. In the spring of 1999, the instrument enclosure on the bridge deck suffered significant damage, due presumably 
to a passing vehicle (Fig. 3.14). Hence, some thought should be given to protecting the enclosure in planning any installation.

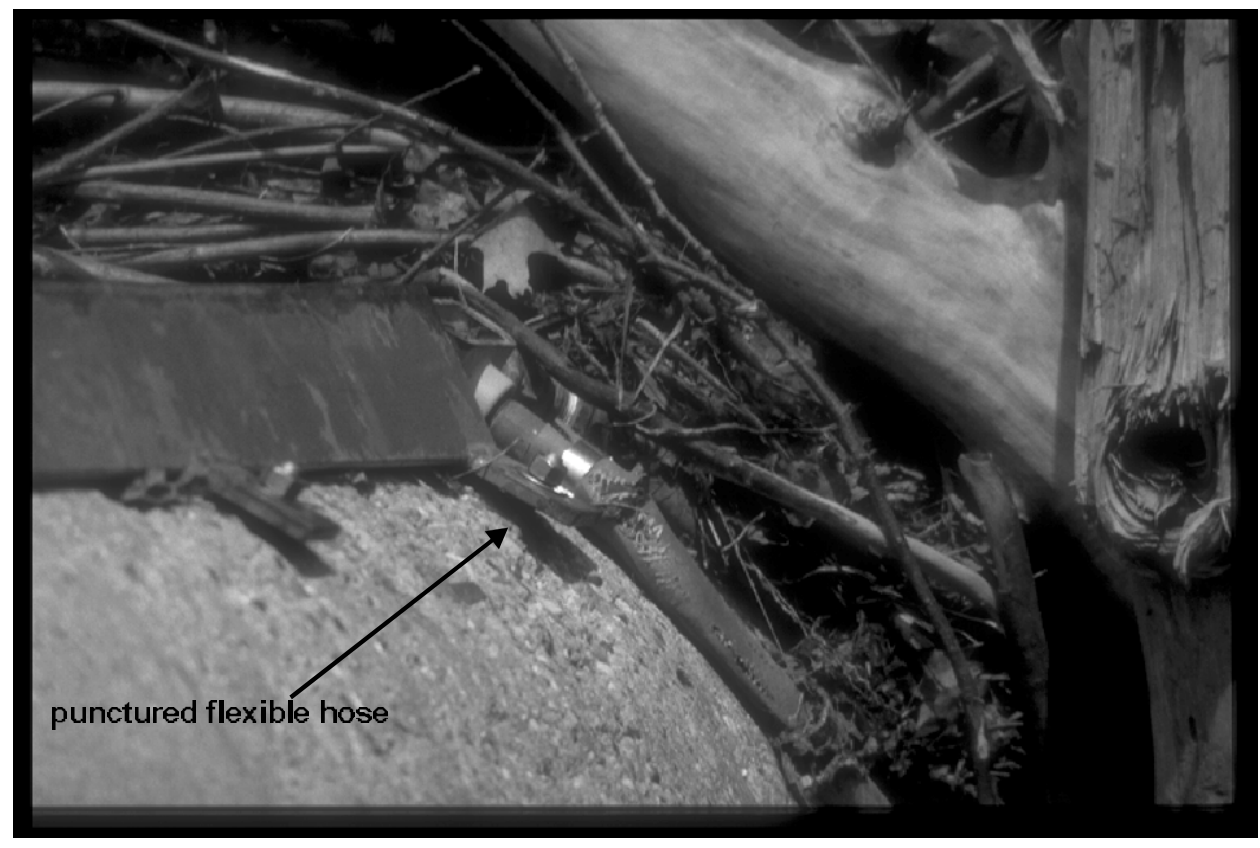

Fig. 3:13 Top view of connection of flexible hose from magnetic-collar device to the protective steel angle showing the puncture in the hose

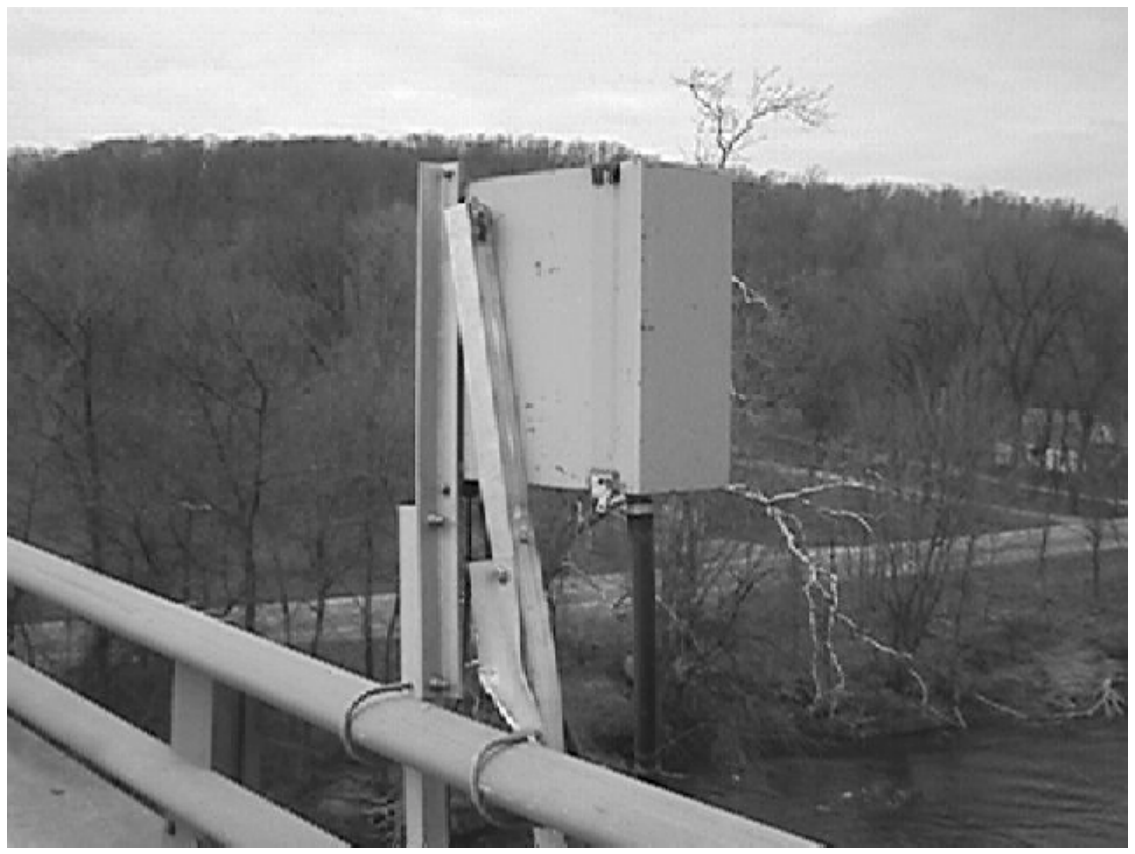

Fig. 3.14 Damage to the instrument enclosure on the bridge deck

The major events occurring during the project period are summarized in Table 3.1. 
Table 3.1 Chronology of notable events during the project period

\begin{tabular}{|l|l|}
\hline Date & Major events \\
\hline Aug. 15, 1996 & Project start date (original project duration: 36 months) \\
\hline Oct. 21, 1996 & Field equipment ordered from ETI \\
\hline May 22 -23,1997 & Instruments first installed at US52 Wabash R. crossing site \\
\hline June 1, 1997 & Beginning of full operation of scour monitors at Wabash R. site \\
\hline June 12, 1997 & $\begin{array}{l}\text { Damage to sonar conduit at US52 Wabash R. site, ruptured cable } \\
\text { to instrument enclosure and interrupted sonar operation }\end{array}$ \\
\hline July 3,1997 & $\begin{array}{l}\text { Inspected damage to Wabash R. site sonar and removal of sonar } \\
\text { for repair in the laboratory }\end{array}$ \\
\hline July 22,1997 & $\begin{array}{l}\text { Sonar at Wabash R. site reinstalled, with steel angle used for } \\
\text { protection of cable instead of original cable conduit }\end{array}$ \\
\hline Nov. 13,1997 & $\begin{array}{l}\text { Installation of scour monitors at the SR25 Wildcat Creek site } \\
\text { completed }\end{array}$ \\
\hline Nov. 21,1997 & $\begin{array}{l}\text { Begin of operation of scour monitors at the SR25 Wildcat Creek } \\
\text { site }\end{array}$ \\
\hline Jan. 22-29,1999 & $\begin{array}{l}\text { Both magnetic collar and sonar devices at the US52 Wabash R. } \\
\text { site observed not to be operating; also the magnetic collar device } \\
\text { at the SR25 Wildcat Creek site observed not to be operating }\end{array}$ \\
\hline April 1, 1999 & $\begin{array}{l}\text { Instrument enclosure at the US52 Wabash R. observed to be } \\
\text { damaged }\end{array}$ \\
\hline April 9, 1999 & $\begin{array}{l}\text { The instrumentation enclosure on the US52 Wabash R. bridge } \\
\text { deck is observed to be damaged, presumably by passing vehicle }\end{array}$ \\
\hline Summer 1999 & $\begin{array}{l}\text { Sonar transducer unit with redesigned housing reinstalled at the } \\
\text { US52 Wabash R. site }\end{array}$ \\
\hline
\end{tabular}

\subsection{Inspection protocol}

The scour monitoring data at both sites were downloaded from the dataloggers by an operator (see Fig. 3.7) at regular intervals, typically weekly. Although this might eventually be performed remotely by means of telemetry, it was preferred in this experimental phase to have regular visits to the sites by an operator, who could at the same time perform routine site inspection. A protocol form was developed for such inspection, and an example is shown in Table 3.2. As can be inferred from the type of questions, the form was aimed primarily at detecting problems that might indicate either problems with the scour-monitoring equipment or with situations, such as the presence of debris at the pier, that might cause mistakes in the scour-monitor data. As can be seen in Table 3.2, floating debris at the pier was quite frequently observed.

\subsection{Downloading the data and the raw data}

At each site, the scour-monitoring data from each device, recorded by the Campbell Scientific CR10X datalogger, can be downloaded via a serial (RS-232) connection to an IBM-compatible laptop computer. The software used was a MS-DOS program, named PC208e. A Windows version of the same program, named PC208w, with basically the same functionality but featuring a more sophisticated and presumably user-friendly graphical user interface, has recently become 
Table 3.2 Inspection record at the US52 Wabash R. site

\begin{tabular}{|c|c|c|c|c|c|}
\hline $\begin{array}{l}\text { Inspection } \\
\text { date }\end{array}$ & $\begin{array}{l}\text { Connection } \\
\text { box }\end{array}$ & $\begin{array}{l}\text { Cable } \\
\text { extension }\end{array}$ & $\begin{array}{l}\text { Sonar \& } \\
\text { sliding collar }\end{array}$ & $\begin{array}{l}\text { Debris or } \\
\text { drift }\end{array}$ & Others \\
\hline & $\begin{array}{l}\text { Rusted or } \\
\text { broken? }\end{array}$ & $\begin{array}{l}\text { Attached or } \\
\text { loose? }\end{array}$ & $\begin{array}{l}\text { Below or } \\
\text { above water? }\end{array}$ & $\begin{array}{l}\text { Lodged on } \\
\text { the pier }\end{array}$ & \\
\hline $02 / 04 / 98$ & $\mathrm{OK}$ & $\mathrm{OK}$ & Above. & Floating trees. & \\
\hline $02 / 10 / 98$ & OK & OK & Above. & Bigger debris. & $\begin{array}{l}\text { Laptop cannot } \\
\text { download }\end{array}$ \\
\hline $02 / 23 / 98$ & OK & OK & Below. & $\begin{array}{l}\text { No debris } \\
\text { above water. }\end{array}$ & \\
\hline $02 / 26 / 98$ & & & & & $\begin{array}{l}\text { INDOT clears } \\
\text { debris. }\end{array}$ \\
\hline $03 / 05 / 98$ & OK & OK & Above & $\begin{array}{l}\text { No debris } \\
\text { above water. }\end{array}$ & \\
\hline $03 / 16 / 98$ & OK & OK & Below & $\begin{array}{l}\text { No debris } \\
\text { above water. }\end{array}$ & \\
\hline $03 / 23 / 98$ & OK & OK & Below & $\begin{array}{l}\text { No debris } \\
\text { above water. }\end{array}$ & \\
\hline $04 / 01 / 98$ & OK & OK & Below & $\begin{array}{l}\text { No debris } \\
\text { above water. }\end{array}$ & \\
\hline $04 / 07 / 98$ & OK & OK & Below & $\begin{array}{l}\text { No debris } \\
\text { above water. }\end{array}$ & \\
\hline $04 / 14 / 98$ & OK & OK & Above & Floating trees. & \\
\hline $04 / 21 / 98$ & OK & OK & $?$ & Floating trees & $\begin{array}{l}\text { Sonar is } \\
\text { covered by }\end{array}$ \\
\hline $04 / 28 / 98$ & OK & OK & $?$ & Floating trees & $\begin{array}{l}\text { Sonar is } \\
\text { covered by }\end{array}$ \\
\hline $05 / 05 / 98$ & OK & OK & $?$ & Floating trees & $\begin{array}{l}\text { Sonar is } \\
\text { covered by }\end{array}$ \\
\hline $05 / 12 / 98$ & OK & OK & Below & $\begin{array}{l}\text { No debris } \\
\text { above water. }\end{array}$ & \\
\hline $05 / 19 / 98$ & OK & OK & Above & $\begin{array}{l}\text { No debris } \\
\text { above water. }\end{array}$ & \\
\hline $05 / 26 / 98$ & OK & OK & Above & $\begin{array}{l}\text { No debris } \\
\text { above water. }\end{array}$ & \\
\hline $06 / 10 / 98$ & OK & OK & Above & $\begin{array}{l}\text { No debris } \\
\text { above water. }\end{array}$ & \\
\hline $06 / 17 / 98$ & OK & Ok & Below & $\begin{array}{l}\text { No debris } \\
\text { above water. }\end{array}$ & \\
\hline
\end{tabular}


available. In view of this, the detailed procedure followed in the project for downloading the data will not be described; rather a general description that would also be applicable to the Windows version is given. A preliminary one-time setup stage is necessary to specify the datalogger involved and the communications characteristics of the data transfer process. After the preliminary setup is or have at an earlier time been completed, data in readable ASCII format can be transferred at the click of a button. Because the CR10X is fully programmable, the data record and hence transferred will depend on the program sent to the datalogger. In the present project, each line of data, representing a hourly recording, contains seven items in commadelimited format, namely, i) a station identifier (1 for the US52 Wabash R. site and 2 for the SR25 Wildcat Creek site), ii) the year, iii) the Julian date, iv) the time (in a 24-hr style), v) the reading from the sliding magnetic-collar device, vi) the reading from the sonar transceiver, and vii) the battery voltage. An extract from a raw data file for the SR25 Wildcat Creek site is shown in Fig. 3. 15.

$$
\begin{gathered}
2,2000,64,1300,3.043,45,11.82 \\
2,2000,64,1400,3.043,45,11.76 \\
2,2000,64,1500,3.043,7,11.44 \\
2,2000,64,1600,3.035,45,11.73 \\
2,2000,64,1700,3.043,45,11.74 \\
2,2000,64,1800,3.036,7.2,11.62 \\
2,2000,64,1900,3.037,7.1,11.62 \\
2,2000,64,2000,3.029,45,11.76 \\
2,2000,64,2100,3.03,7.3,11.5 \\
2,2000,64,2200,3.03,45,11.83
\end{gathered}
$$

Fig. 3.15 Extract from a raw data file transferred from the CR10X datalogger

On the first line, the meaning of the numbers from left to right are: 2 identifies the data as being from the SR25 Wildcat Creek site, 2000, 64, 1300 are the year, the Julian date, and the time the data were recorded (i.e., 1:00 pm on 14 March 2000), 3.043 and 45 are the reading from the magnetic-collar and the sonar devices respectively, and 11.82 is the battery voltage. It might be noted that the sonar readings fluctuate widely in Fig. 3.15; the 45 reading in fact indicates a false reading, likely due either to the effect of debris or to the fact that the sonar transceiver was not submerged. Similarly, if the magnetic-collar device is not working properly, this is usually associated with large positive or negative numbers that are readily identifiable. The raw data from the two different devices are not directly comparable, but is later adjusted by adding a constant to the magnetic-collar reading based on readings obtained at the time of installation. If the battery voltage is below $10 \mathrm{~V}$, then this also indicates possible problems. The above data can be easily imported into standard spreadsheet or other types of software for further adjustment or analysis. 


\section{Chapter 4: The scour-monitoring data}

One of the main objectives of the present work was the evaluation of the scour-monitoring capabilities of the sliding magnetic-collar and the sonar devices. This entails an examination of the data measured by these devices for their signal characteristics and an attempt to relate the data to distinct hydrological events. Moreover, the installation of the two different devices at each site permits not only a comparison of the two devices but also a valuable check that each device is operating properly. Flow data used to identify hydrological events were based on data from nearby USGS gaging stations (station no. 03335000 for the Wildcat Creek site, station no. 03335500 for the Wabash R. site) and available on the Internet at the following sites:

- Wildcat Creek: www-dinind.er.usgs.gov/rt-cgi/gen_stn_pg?station=03335000

- Wabash River: www-dinind.er.usgs.gov/rt-cgi/gen_stn_pg?station=03335500

Flood stage at the Wildcat Creek gaging station is declared at a stage of $10 \mathrm{ft}$ when the discharge is 5,430 cfs, while flood stage at the Wabash R. station is declared at a stage of $11 \mathrm{ft}$ when the discharge is 17,300 cfs. The USGS gaging station on Wildcat Creek near Lafayette is less than 2 miles upstream of the SR25 Wildcat Creek site, while the USGS gaging station on the Wabash R. at Lafayette is less than 1 mile downstream of the US52 Wabash R. site.

\subsection{General characteristics of the signal from the devices}

Typical extracts of scour-monitoring time series data for the two sites are shown in Fig. 4.1 for March 1998. The date is plotted on the $x$-axis; since measurements are taken every hour, there are 24 data points between each date interval. The reading of the devices are plotted on the $y-$ axis. The device reading is derived from the raw data recorded on the datalogger (see the discussion of the raw data in the previous chapter), but has been adjusted such that both devices initially gave the same reading (for the US52 Wabash R. site, this initial reading was $\approx 11.5 \mathrm{ft}$, while for the SR25 Wildcat Creek site, this initial reading was $\approx 4.7 \mathrm{ft}$ ). An increase in the reading indicates that scour has occurred. Thus, in Fig. 4.1a, the magnetic collar reading at the SR25 Wildcat Creek site is seen to be initially at $\approx 4.7 \mathrm{ft}$, but increases to $\approx 5.7 \mathrm{ft}$, implying that 1-ft of scour has been recorded by the magnetic collar. Similarly, at the US52 Wabash R. site, the magnetic collar is already at $13 \mathrm{ft}$ at the beginning of March, indicating that $1.5 \mathrm{ft}$ of scour had already occurred since installation. Scour events will be discussed in more detail below; the present section will merely point out qualitative features of the different signals.

Due to its design as a maximum-measuring device, the sliding magnetic collar should ideally give a reading that is always non-decreasing, since the collar should either remain at a given location in which case the signal should not change, or the collar should slide farther down the steel rod during a scour event in which case the reading should increase. The limited resolution of this device ( $0.5 \mathrm{ft}$, see Chap. 2) also entails that changes should occur in discrete jumps that are multiples of $0.5 \mathrm{ft}$. In Fig. 4.1, these features are clearly seen in the magnetic-collar records at both sites. In contrast, because the sonar is capable of responding to temporal variations in streambed level, the sonar reading may fluctuate constantly. This is especially seen in the US52 Wabash R. site record. The very short-term hourly fluctuations may for the present purposes be considered as noise, due to a variety of sources, including possibly real short-term fluctuations in bed levels. Longer-term variations occurring over several days are also clearly observed in Fig. 
$4.1 \mathrm{~b}$, and likely reflect the real cycle of scour and fill. It is to be noted that the sonar reading is less than the collar reading over much of the month. This suggests that the scour hole had filled back in, such that the collar was buried, while the sonar device, able to respond to filling in, gave a reading below that of the collar.

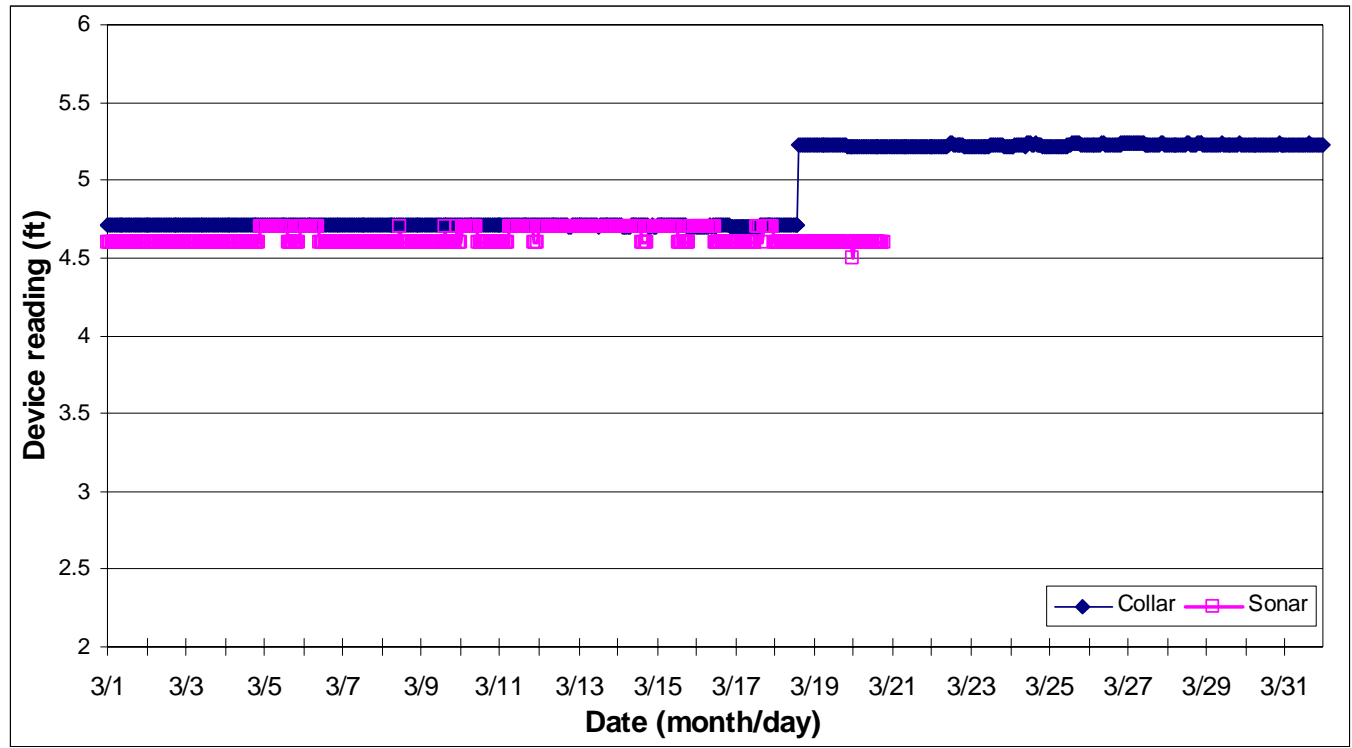

(a)

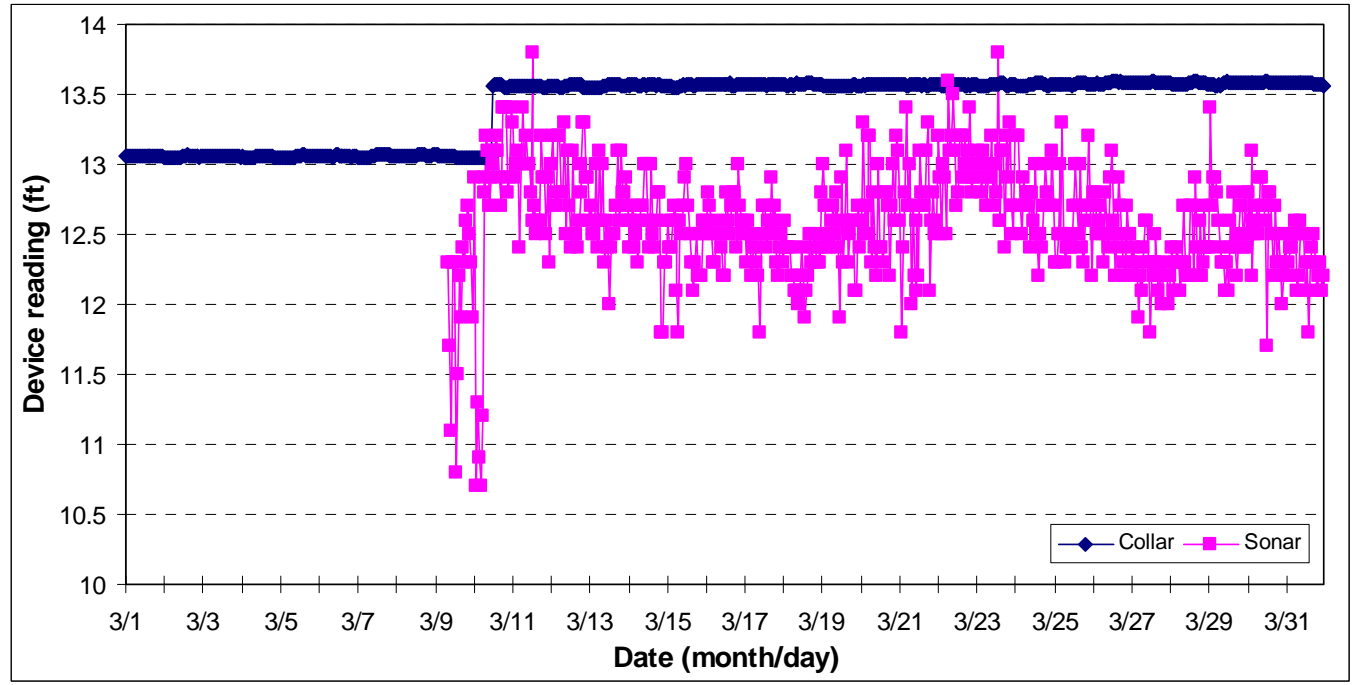

(b)

Fig. 4.1 Time series of scour-monitoring data from the two sites for March 1998:

a) Wildcat Creek and b) Wabash R.

Two other features of Fig. 4.1 may be remarked. Firstly, at both sites, there were gaps in the record from the sonar device. Such gaps are most often though not always due to the sonar not recording useful data because of not being submerged during low-flow periods. The other feature worthy of note is the difference between the records at the two sites. Whereas the sonar readings at the SR25 Wildcat Creek indicate little or no change in bed levels, the readings at the US52 Wabash R. site indicate a quite active bed. Also though the magnetic-collar device 
recorded new maximum scour at each site during the month, the dates when these occurred at the two sites differed by more than a week, in spite of the relative geographical closeness of the two sites (they are less than 10 miles apart).

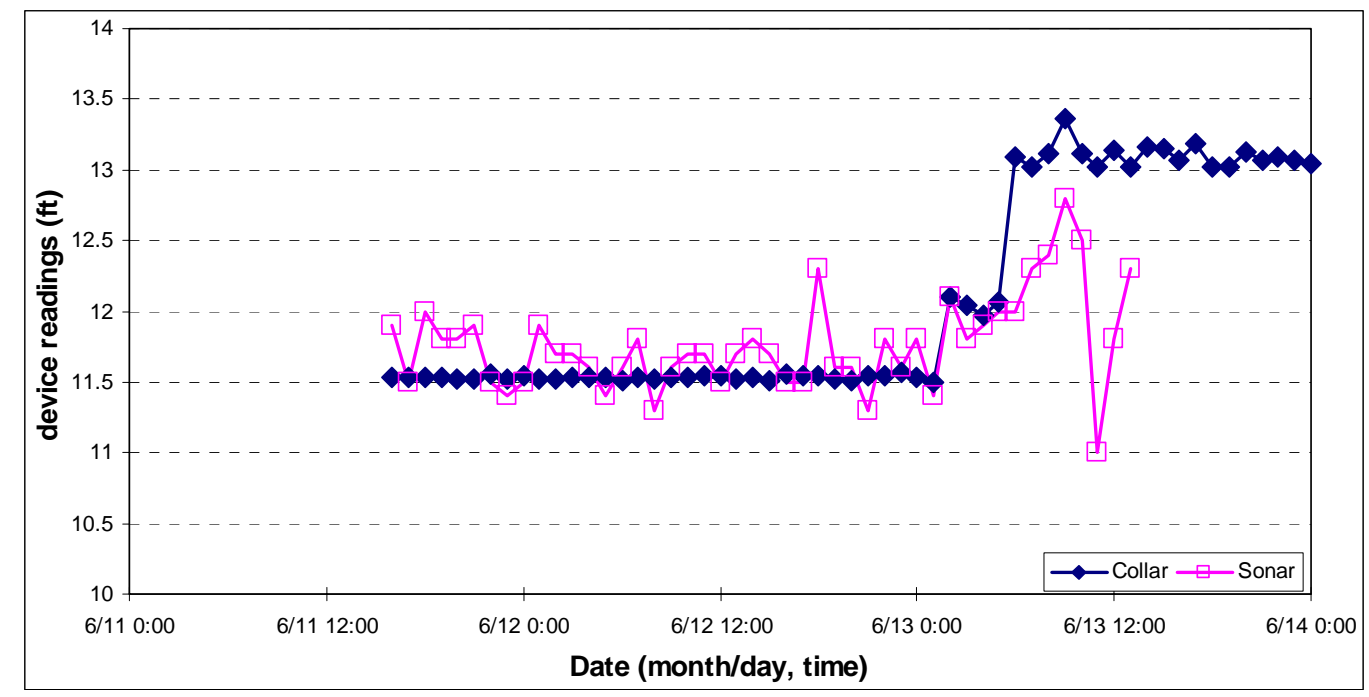

Fig. 4.2 Close-up of time series of device readings at the US52 Wabash R. site immediately after installation (from June 12 to June 14, 1997)

The consistency between sonar and magnetic-collar readings deserves some comments. Because of the difference in types of measurements performed by the two different devices, the two signals will not track each other. Only in the case where the magnetic-collar device detects further scour should the sonar also detect further scour; if the magnetic-collar device reading remains constant, the sonar reading can detect scour or fill but it should be below the magneticcollar reading. In Fig. 4.1a, the magnetic-collar device detects scour during 3/19, but the sonar reading remains constant until 3/22, after which the signal disappears. This inconsistent behavior of the sonar is attributed to the effect of debris, which was a continual source of problems at the SR25 Wildcat Creek site. Although some evidence of corresponding increase in device readings is found in Fig. 4.1b, the noise in the sonar time series precludes any definitive conclusion. Consistency between the two devices is more clearly seen in Fig. 4.2, a short extract of the time series at the US52 Wabash R. site immediately after installation of the devices, when the two devices should track each other because no history of scour has as yet occurred. The two signals track each other, remaining constant until 6/13 0:00, and then both increasing after 6/13 0:00. Unfortunately, the sonar failed soon thereafter, with a tell-tale sharp dip shortly before noon $6 / 13$.

\subsection{Relation to hydrological events: the US52 Wabash R. site}

The time series of the scour-monitoring data are plotted with the corresponding discharge and stage data for the US52 Wabash R. site in Figs. 4.3-4.4 for 1997 and 1998. It may be recalled that flood stage is declared when the stage exceeds $11 \mathrm{ft}$. In the first year of operation, 1997, only a single real flood was recorded, soon after installation of the scour-monitoring devices, and in fact caused the sonar to fail by rupturing the cable to the datalogger (see the previous chapter). 
This explains the gap in sonar reading after 6/13. On the other hand, the gaps seen in the magnetic-collar readings at $7 / 15$ and $8 / 23$ are due to the failure of the battery power. It should also be recalled that the sonar device operates only when it is submerged, but this occurs only when the stage exceeds $\approx 8 \mathrm{ft}$. Because the stage was less than this level over much of the year, the sonar gave only sporadic meaningful results. At isolated points, sonar readings were significantly larger than the magnetic-collar readings, but these are thought to be unreliable.

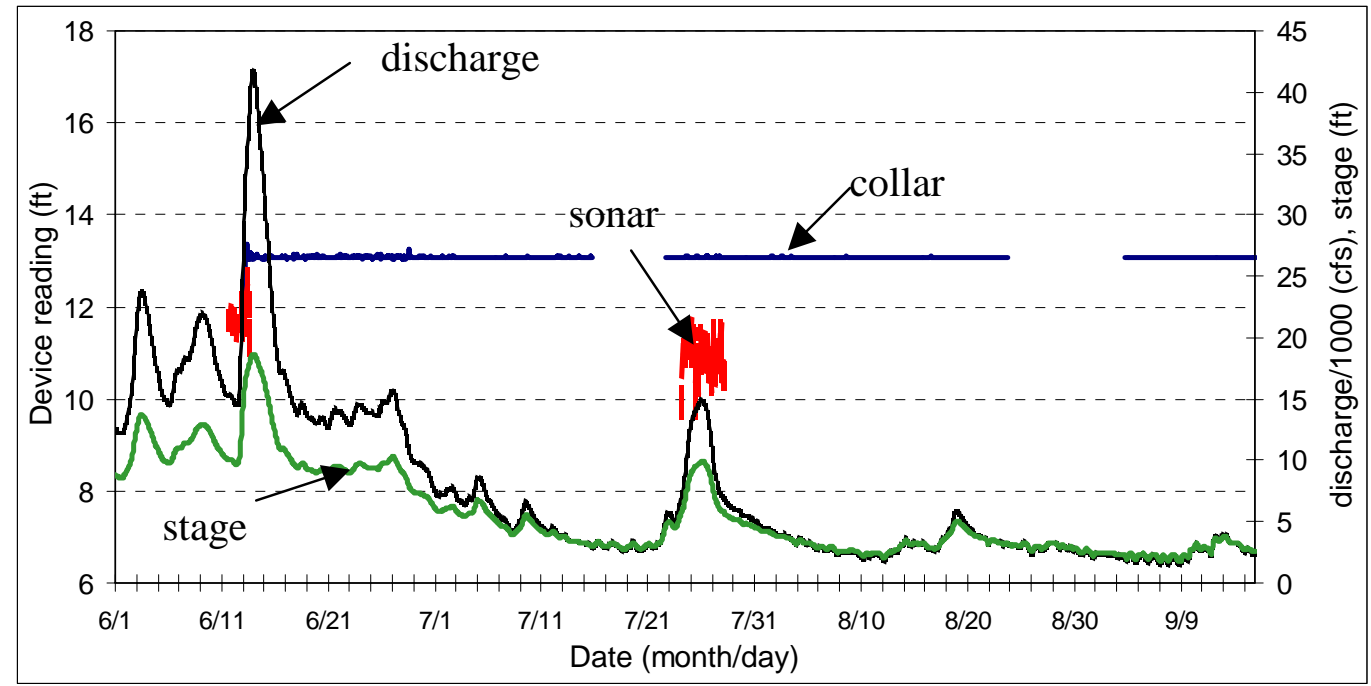

(a)

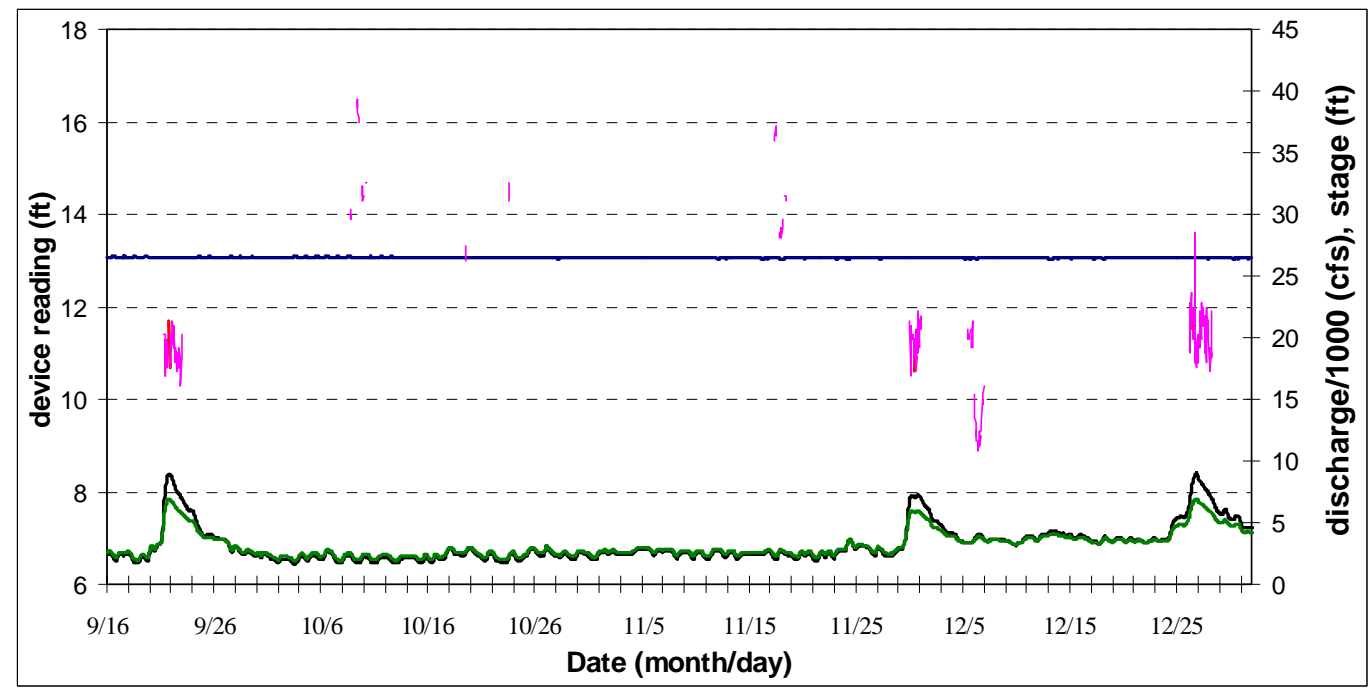

(b)

Fig. 4.3 Time series of scour-monitoring device readings together with the corresponding discharge and stage at the US52 Wabash R. site for 1997 


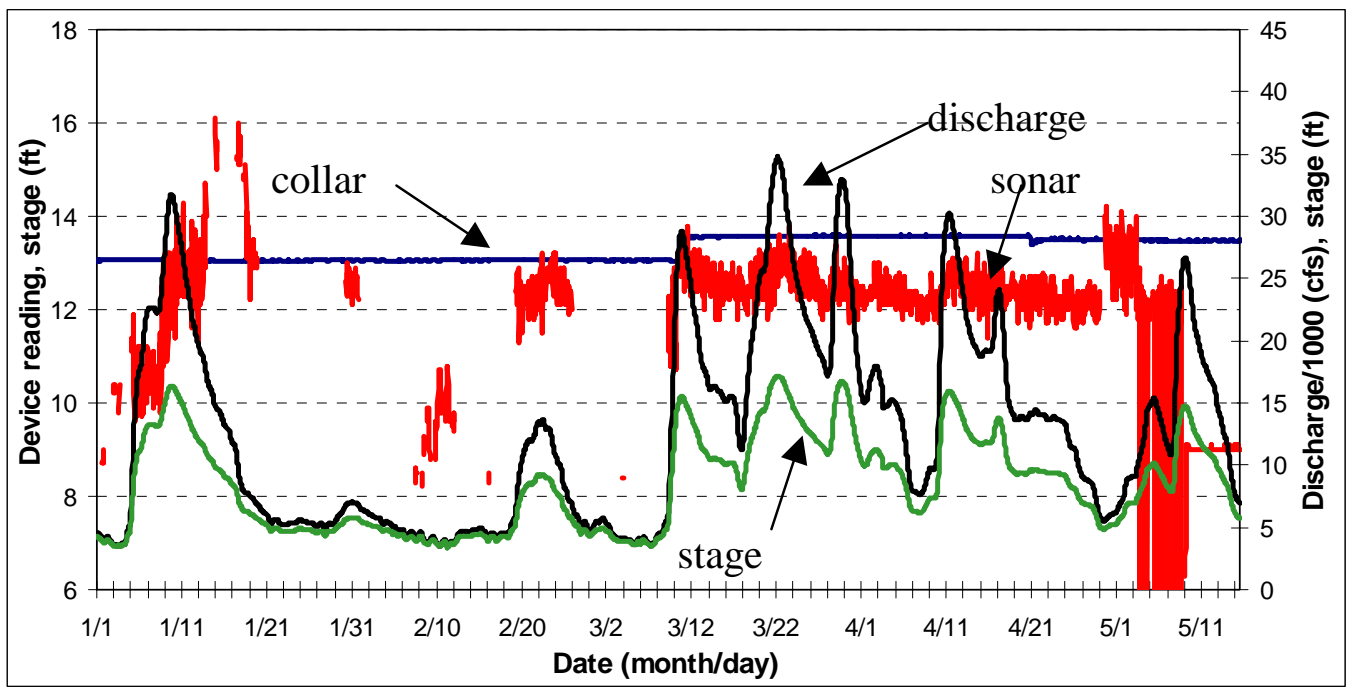

(a)

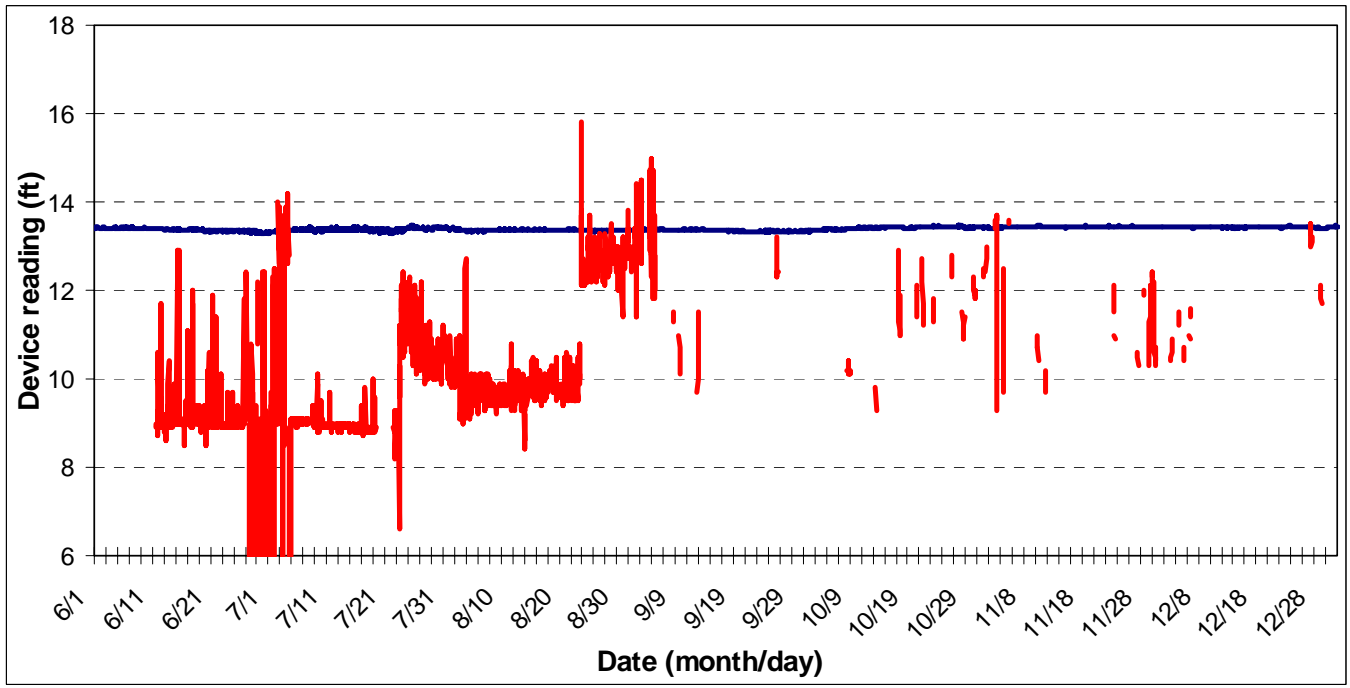

(b)

Fig. 4.4 Time series of scour-monitoring device readings together with the corresponding discharge and stage at the US52 Wabash R. site for 1998

In the first half of 1998, several flood events were recorded (Fig. 4.4a). It is notable that the increase in maximum scour recorded by the magnetic-collar device did indeed coincide with a flood event, though it is also noteworthy that other comparable or even larger events did not result in any change in the magnetic-collar device reading. Gaps in the sonar record are again attributed to low-flow stages when the device is not submerged. A fairly strong positive correlation may be noted between the hydraulic variables, discharge and stage, and the sonar reading, with increases in sonar reading (indicating local scour) being associated with higher discharges. At the beginning of May, the sonar reading becomes quite erratic, and this continues into August and possibly beyond. This is attributed to the effect of debris accumulation, which, while less common than at the SR25 Wildcat Creek site, still occurred at the US52 Wabash R. site. 
The magnetic-collar device reading however remains unchanged throughout the rest of the year. Unfortunately, the corresponding hydrologic data for the second half of the year was apparently not downloaded and so were not plotted. An effort will be made to acquire this data for the final draft of this report. Nevertheless, since flood events are generally less likely in the second half of the year (during the summer and fall months), the magnetic-collar device readings are quite plausible.

As already reported in the previous chapter, both devices were lost in late January 1999, and the replacement sonar device was only installed in the summer of 1999. As such, no worthwhile data was collected in 1999 at the US52 Wabash R. site.

\subsection{Relationship to hydrologic events: the SR25 Wildcat Creek site}

The time series record for the SR25 Wildcat Creek site from the time of installation to the end of 1998 is shown in Fig. 4.5. Up to the end of February 1998, no significant change in the magnetic-collar device reading is observed, although a high-flow event (though not technically a flood event) did occur. The sonar behaves rather erratically, and in particular, at approx. 2/15, large (negative) spikes, typical signature of the effect of debris, are observed. Between 3/1 and $5 / 15$, several high-flow events, including three flood events, occurred, only one of which (the largest) resulted in any change in the magnetic-collar device. After 5/15, the magnetic-collar device recorded two more maximum-scour events, one on $6 / 12$ and the other on $8 / 29$, the latter yielding a surprisingly large 1-ft increase. Unfortunately, the hydrologic data during this time was not obtained. It might have been expected, as has been argued in the preceding section with regards to the US52 Wabash R. site, that, during this drier period of the year, scour events would not occur. Interestingly, the magnetic-collar device exhibited some erratic behavior at about the same time as the first maximum-scour event during this period, though it apparently recovered and behaved normally thereafter. During the entire year, the sonar, plagued by debris accumulation, provided no useful results.

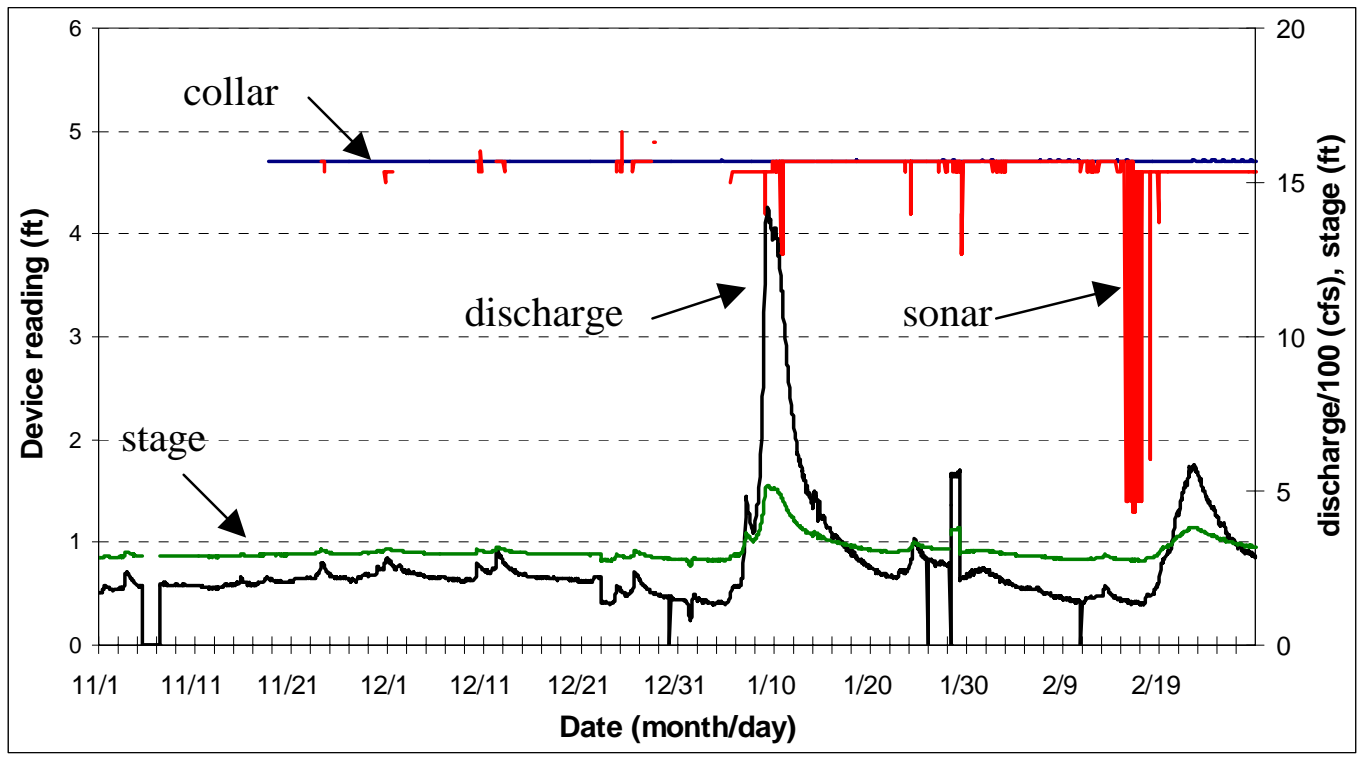

(a) 


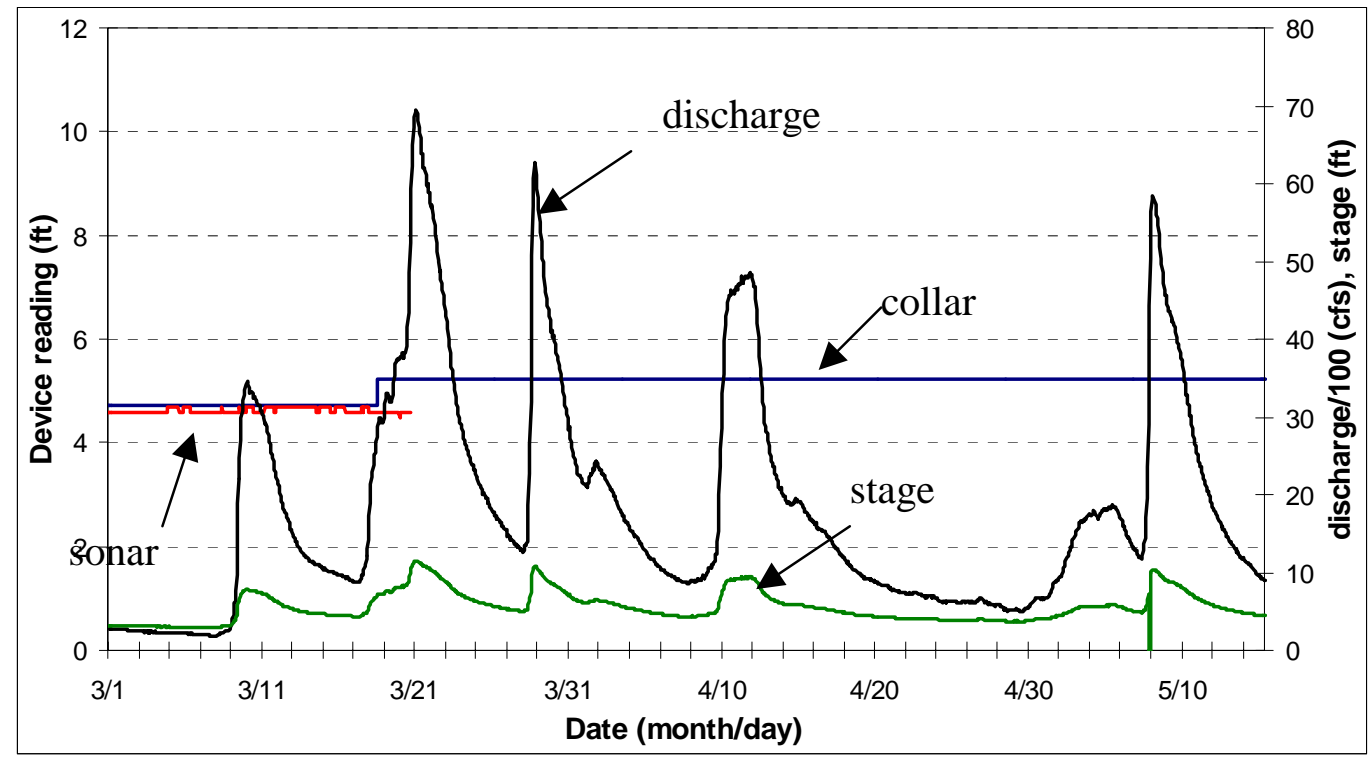

(b)

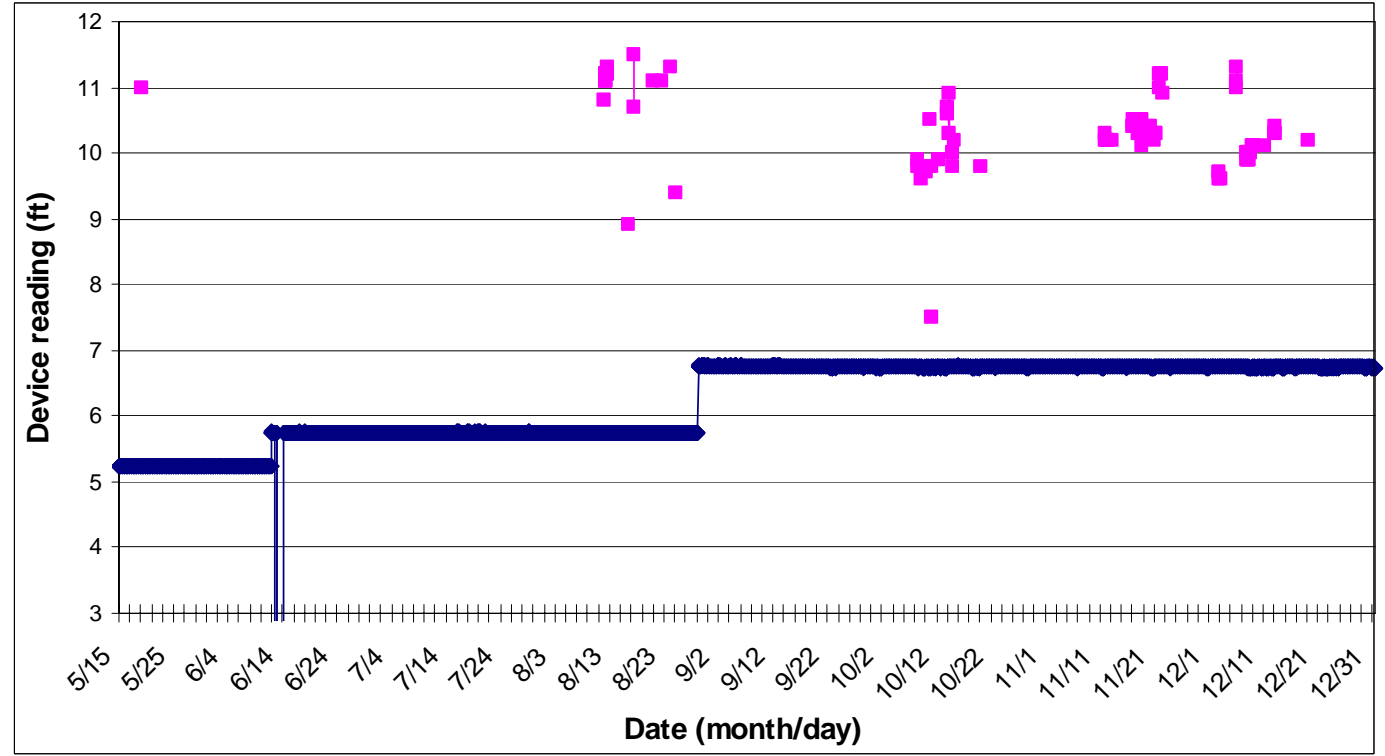

(c)

Fig. 4.5 Time series of data from scour-monitoring devices and the corresponding hydrologic data (discharge and stage) when available

\subsection{The scour-monitoring data and implications for pier scour}

The scour around bridge piers is a complicated and hence ill-understood phenomenon, which might depend on a large number of hydraulic, sediment and pier characteristics. Data from scour-monitoring devices may provide valuable field information that might contribute not only to improvements in theoretical, and numerical models in the future, but also solidify the empirical basis of current engineering practice. Although the amount of data so far obtained is insufficient to draw any definitive conclusions regarding pier scour, it is sufficient to raise some interesting questions. In Fig. 4.4a, the event triggering the new maximum scour is not necessarily the largest in magnitude (stage or discharge). The largest flood during the period 
when hydrologic data were available, that occurring soon after installation, did not actually result in the maximum scour (Fig. 4.3a) during the period. Rather, new maxima resulted from floods of smaller magnitude. At the SR25 Wildcat Creek site, a new scour maximum was recorded (Fig. 4.5b) before the flood peak was reached. Are these merely an artifact of the nature of the measuring instrument, the sliding magnetic-collar device? If not, then this may have implications for the evaluation of scour for the design of bridges, which are currently predicated primarily on the magnitude of the flood (either stage or discharge). 


\section{Summary and conclusions}

\subsection{Summary}

A field study was conducted to evaluate the performance of two devices intended to monitor continuously without human intervention the maximum local scour around a bridge pier. The first device is based on a magnetic collar on a stainless steel pipe driven into the streambed, such that the collar rests on the streambed but is free to slide down the rod when a scour event erodes the supporting bed. The location of the collar, and hence the maximum scour, is determined by sensing the magnetic field of the collar with an resistor-switch array in an insert inside the pipe. The second device is a sonar device, with a transceiver mounted on the pier, which when submerged emits an acoustic signal that is reflected back from the streambed. The distance from the transceiver to the streambed can therefore be determined. In contrast to the sliding magneticcollar device, which only measures the maximum scour, the sonar device can provide information about not only scour but also subsequent fill. Both devices were installed at two different sites, on the SR25-Wildcat Creet crossing and on the US52-Wabash R. crossing, and so a direct comparison of the two devices could be made. As is typical, the devices were installed at the upstream nose of one of the central piers. The main installation problem occurred at the US52 Wabash R. site because of the unusually high bridge deck relative to the river stage. Even when fully extended, the REACH-ALL could not cover the entire distance.

The first installation at the US52 Wabash R. site was completed in June 1997. The sonar device failed a few days afterwards during the first flood, which severed the cable from the sonar to the datalogger. In response to this failure, the cables were subsequently encased in a steel angle. This was also adopted at the SR25 Wildcat Creek site, where the first installation was completed in November 1997. In January 1999, both devices at the US52 Wabash R. site and the magneticcollar device at the SR25 Wildcat Creek site failed. At the US52 Wabash R. site, the cable from the magnetic-collar device, which is exposed to the flow beneath the water surface, had been completely severed, and so that device was totally lost. The sonar had apparently been washed away completely. A new sonar transceiver was re-installed in the summer of 1999 with a modified mount design that is now integrated with the steel angle that was originally used for armoring the cables. At the SR25 Wildcat Creek site, the cable from the magnetic-collar device was punctured, thus interrupting the signal. This was repaired, but its long-term survivability is rather questionable.

\subsection{Conclusions and recommendations}

In addition to providing an opportunity to gain experience in field installation of these scourmonitoring devices, the field study dealt with two broad and somewhat related issues:

- the survivability of the scour-monitoring devices under conditions to be encountered in Indiana streams

- the reliability of the scour-monitoring devices in yielding useful data regarding scour at bridge piers, particularly in relation to bridge hydraulics data

With regards to these issues, the following points may be made: 
- The survivability of the sonar, with the modifications made in the course of the project, viz. the steel angle and the modified mount, is still not clear because of the limited time that it has been installed. The study should be extended in order to test the modifications made.

- The survivability of the sliding magnetic-collar device was rather surprisingly better than the sonar device (in its initial form). Nevertheless, one of the collar devices is lost, while the outlook for the other is not promising. The main problem lies in the cable to the datalogger, which for a certain length is wholly exposed to the flow without any protection. ETI, the company marketing the scour monitors, indicates that they are developing a model that would not need cables for communication purposes, which would eliminate this problem.

- Even apart from its impact on survivability, the problem of woody debris being trapped, or accumulating at bridge piers, must be dealt with if the scour monitors are to operate reliably. The sonar device at the SR25 Wildcat Creek has as yet not provided any useful data because of difficulties attributed to the effect of woody debris.

- When operating under normal conditions, the two devices can give useful information regarding the development of local scour at the installation location. The readings from the two devices are generally consistent with one another, and also are plausible when considered in relation to the corresponding time series of hydrologic data. A more detailed study of the relationship between scour-monitoring data and hydrological data would be desirable with a larger sample of flood events. 


\section{References}

1. Richardson, E. V., Simon, D. B., and Julien, P. Y. (1990). Highways in the river environment, Publication no. FHWA-IP-90-016, U. S. Dept. of Transportation, Federal Highway Administration, Washington, D. C.

2. Richardson, E. V. , Harrison, L. J. and Davis, S. R. (1991) Evaluating scour at bridges, Publication no. FHWA-IP-90-017, Hydraulic Engineering Circular No. 18, U. S. Dept. of Transportation, Federal Highway Administration, Washington, D. C.

3. Lagasse, P. F., Richardson, E. V., Schall, J. D., and Price, G. R. (1997). Instrumentation for measuring scour at bridge piers and abutments, Transportation Research Board, Rept. 396, National Academy Press, Washington, D. C.

4. Schall, J. D., Price, G. R, Fisher, G. A., Lagasse, P. F., and Richardson, E. V. (1997a). Sonar scour monitor, Transportation Research Board, Rept. 397A, National Academy Press, Washington, D. C.

5. Schall, J. D., Price, G. R, Fisher, G. A., Lagasse, P. F., and Richardson, E. V. (1997b). Magnetic sliding collar scour monitor, Transportation Research Board, Rept. 397B, National Academy Press, Washington, D. C. 


\section{Appendix 1: CR10X Data acquisition program}

The following CR10X program controls the data acquisition and data storage process. Once every hour, the program initiates the powering up of the sonar and then waits for ten seconds allowing the sonar readings to stabilize before recording the data. Before storing the data, the program checks for ten consecutive consistent readings to ensure that the data do not result from spurious signals. The program then takes the readings from both the sonar and sliding collar devices and stores the readings in the CR10X memory along with time and date information as well as battery voltage for power outage indication. After the data are stored, the program powers down the sonar in order to conserve battery power.

$;\{\mathrm{CR} 10 \mathrm{X}\}$

;Program:Purdue Combined Scour Tracker Wabash \& 52 Bridge

;Version Date 3/20/97

;Flag Usage: Flag 1 - Start reading sensors.

;Input Channel Usage: 1H-Sliding Collar Voltage

;Excitation Channel Usage: $1=\mathrm{Ch} 1$

;Control Port Usage: C1 - Sonar/SC100 DTR

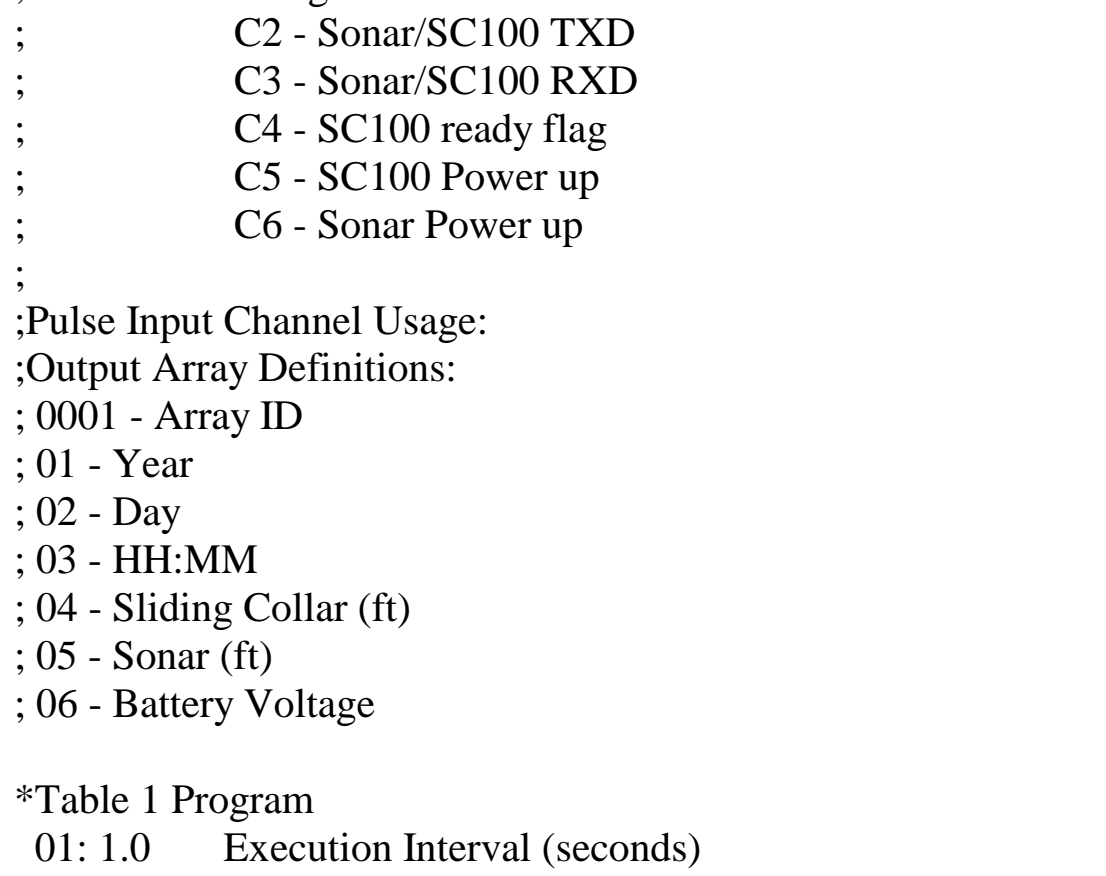

1: If time is (P92); Check if time is on the hour.

1: $0 \quad$ Minutes (Seconds --) into a

2: $60 \quad$ Interval (same units as above)

3: 30 Then Do

2: Timer (P26); Reset timer.

1: $0 \quad$ Reset Timer 

3: $\mathrm{Z}=\mathrm{F}(\mathrm{P} 30)$
1: $0 \quad \mathrm{~F}$
2: $00 \quad$ Exponent of 10
3: 19 Z Loc [C_Count ]
4: $\mathrm{Z}=\mathrm{F}(\mathrm{P} 30)$
1: $0 \quad \mathrm{~F}$
2: $00 \quad$ Exponent of 10
3: 20 Z Loc [S_Count ]

5: Do (P86) ; $\quad$ Power up SC100 interface.

1: $55 \quad$ Set Port 5 Low

6: Do (P86) ;

1: $46 \quad$ Set Port 6 High

7: End (P95)

8: Timer (P26) ;

1: 1 Loc [ timer ]

9: $\mathrm{IF}(\mathrm{X}<=>\mathrm{F})(\mathrm{P} 89)$

1: $1 \quad \mathrm{X}$ Loc [ timer ]

2: $1=$

3: $10 \quad \mathrm{~F}$

4: 30 Then Do

10: Do (P86) ;

1: $01 \quad$ Call Subroutine 1;

11: End (P95)

12: $\mathrm{IF}(\mathrm{X}<=>\mathrm{F})(\mathrm{P} 89)$;

1: $1 \quad \mathrm{X}$ Loc [ timer ] ; than thirty seconds.

$2: 1=$

3: $30.0 \quad \mathrm{~F}$

4: $11 \quad$ Set Flag 1 High

13: If Flag/Port (P91) ;

1: $11 \quad$ Do if Flag 1 is High

2: 30 Then Do

14: Excite-Delay (SE) (P4) ; $\quad$ Read sliding collar sensor.
Call SC100 initialization subroutine.

Check if timer is greater

Store timer reading.

Power up sonar.

Start reading sensors. 
2: 5 ก̃ $2500 \mathrm{mV}$ Slow Range

3: $1 \quad$ SE Channel

4: $01 \quad$ Excite all reps w/Exchan 1

5: 10 Delay (units $0.01 \mathrm{sec}$ )

6: $2500 \mathrm{mV}$ Excitation

7: 2 Loc [ N_Collar ]

8: .0004 Mult

9: $0 \quad$ Offset

15: BR Transform Rf[X/(1-X)] (P59)

1: $1 \quad$ Reps

2: 2 Loc [ N_Collar]

3:21.8 Multiplier (Rf)

16: If Flag/Port (P91) ; $\quad$ Check if SC100 is ready to send.

1: $44 \quad$ Do if Port 4 is High

2: 30 Then Do

17: Port Serial I/O (P15) ; $\quad$ Read sonar sensor.

1: $1 \quad$ Reps

2: 01 ASCII/RS-232, 1200 Baud

3: 1 Delay (0.01 seconds)

4: $1 \quad$ First Control Port

5: 39 Output Loc [ null ]

6: $1 \quad$ No. of Locs to Send

7: 102 Termination Character

8: 10 Maximum Characters

9: 1000 CTS/Input Wait

10: 3 Loc [N_Sonar ]

11: $1.0 \quad$ Mult

12: 0.0 Offset

18: End (P95)

19: $\mathrm{Z}=\mathrm{X}-\mathrm{Y}(\mathrm{P} 35)$;

1:2 X Loc [ N_Collar ]

2: 15 Y Loc [ P_Collar ]

3: 16 Z Loc [ D_Collar ]

20: $\mathrm{Z}=\mathrm{ABS}(\mathrm{X})(\mathrm{P} 43) ; \quad$ Absolute difference.

1: 16 X Loc [D_Collar ]

2: 16 Z Loc [D_Collar ]

Check for difference in readings

21: $\mathrm{Z}=\mathrm{X}-\mathrm{Y}(\mathrm{P} 35)$

1: 3 X Loc [ N_Sonar ]

2: 17 Y Loc [ P_Sonar ]

3: 18 Z Loc [D_Sonar ] 
22: $\mathrm{Z}=\mathrm{ABS}(\mathrm{X})(\mathrm{P} 43)$

1: 18 X Loc [D_Sonar ]

2: 18 Z Loc [D_Sonar ]

23: IF $(\mathrm{X}<=>\mathrm{F})(\mathrm{P} 89)$; $\quad$ Check that difference is less

1: $16 \quad$ X Loc [D_Collar ]; than $0.5 \mathrm{ft}$.

2: $4<$

$3: 2 \quad \mathrm{~F}$

4: $30 \quad$ Then Do

24: $\mathrm{Z}=\mathrm{Z}+1(\mathrm{P} 32)$;

Increment count if difference

1: 19 Z Loc [C_Count ]; is less than $0.5 \mathrm{ft}$

25: Else (P94)

26: $\mathrm{Z}=\mathrm{X}(\mathrm{P} 31)$;

$1: 2 \quad X$ Loc [N_Collar ];

Otherwise make previous reading

2: 15 Z Loc [ P_Collar ]

27: $\mathrm{Z}=\mathrm{F}(\mathrm{P} 30)$; $=$ new reading.

1: $0 \quad \mathrm{~F}$

2: $00 \quad$ Exponent of 10

3: 19 Z Loc [ C_Count ]

28: End (P95)

19: $\mathrm{IF}(\mathrm{X}<=>\mathrm{F})(\mathrm{P} 89)$

1: 18 X Loc [D_Sonar ]

2: $4<$

3: $0.5 \quad \mathrm{~F}$

4: $30 \quad$ Then Do

29: $\mathrm{Z}=\mathrm{Z}+1$ (P32)

1: 20 Z Loc [ S_Count ]

30: Else (P94)

31: $\mathrm{Z}=\mathrm{X}(\mathrm{P} 31)$

$1: 3 \quad X$ Loc [N_Sonar ]

2: $17 \quad$ Z Loc [ P_Sonar ]

32: $\mathrm{Z}=\mathrm{F}(\mathrm{P} 30)$

1: $0 \quad \mathrm{~F}$

2: $00 \quad$ Exponent of 10

3: 20 Z Loc [ S_Count ]

33: End (P95) 
34: IF $(\mathrm{X}<=>\mathrm{F})(\mathrm{P} 89)$; If 10 consistant readings are

1: 19 X Loc [ C_Count ] ; acheived, then store data.

2: $3 \quad>=$

3: $10 \quad \mathrm{~F}$

4: 30 Then Do

35: IF $(\mathrm{X}<=>\mathrm{F})(\mathrm{P} 89)$

1: 20 X Loc [S_Count ]

2: $3 \quad>=$

3: $10 \quad \mathrm{~F}$

4: 30 Then Do

36: Batt Voltage (P10); $\quad$ Read battery voltage.

1: $21 \quad$ Loc [ Battery ]

37: Do (P86)

1: $10 \quad$ Set Output Flag High (Flag 0)

38: Set Active Storage Area (P80)

1: $01 \quad$ Final Storage Area 1

2: 0001 Array ID

39: Real Time (P77)

1: 1220 Year,Day,Hour/Minute (prev day at midnight, 2400 at midnight)

40: Sample (P70)

1: 2 Reps

2: 2 Loc [N_Collar ]

41: Sample (P70)

1: $1 \quad$ Reps

2: $21 \quad$ Loc [ Battery ]

42: Do (P86) ; $\quad$ End reading sensors

1: $21 \quad$ Set Flag 1 Low

43: Do (P86) ; $\quad$ Power down sonar.

1: $56 \quad$ Set Port 6 Low

44: Do (P86) ; $\quad$ Power down SC100 interface.

1: $45 \quad$ Set Port 5 High

45: End (P95)

46: End (P95) 
47: End (P95)

*Table 2 Program

02: $0.0 \quad$ Execution Interval (seconds)

*Table 3 Subroutines

1: Beginning of Subroutine (P85)

1: $01 \quad$ Subroutine 1; Initialize SC100 interface.

2: $\mathrm{Z}=\mathrm{F}(\mathrm{P} 30)$; $\quad$ Commands for initializing

1: $17 \quad \mathrm{~F} ; \quad$ search/find \& replace.

2: $00 \quad$ Exponent of 10

3: 22 Z Loc [ctrl_Q ]

3: $\mathrm{Z}=\mathrm{F}(\mathrm{P} 30)$

1: $73 \quad \mathrm{~F}$

2: $00 \quad$ Exponent of 10

3: 23 Z Loc [ I ]

4: $\mathrm{Z}=\mathrm{F}(\mathrm{P} 30)$

1: $49 \quad \mathrm{~F}$

2: $00 \quad$ Exponent of 10

3: 24 Z Loc [ one ]

5: $\mathrm{Z}=\mathrm{F}(\mathrm{P} 30)$; $\quad$ First search character (D)

1: $68 \quad \mathrm{~F}$

2: $00 \quad$ Exponent of 10

3: 25 Z Loc [D1 ]

6: $\mathrm{Z}=\mathrm{F}(\mathrm{P} 30)$; $\quad$ Second search character (D)

1: $68 \quad \mathrm{~F}$

2: $00 \quad$ Exponent of 10

3: 26 Z Loc [ D2 ]

7: $\mathrm{Z}=\mathrm{F}(\mathrm{P} 30)$;

1: $66 \quad \mathrm{~F}$

2: $00 \quad$ Exponent of 10

3: 27 Z Loc [B ]

Third search character (B)

8: $\mathrm{Z}=\mathrm{F}(\mathrm{P} 30)$;

1: $84 \quad \mathrm{~F}$

2: $00 \quad$ Exponent of 10

3: $28 \quad \mathrm{Z} \operatorname{Loc}[\mathrm{T}]$

9: $\mathrm{Z}=\mathrm{F}(\mathrm{P} 30)$; $\quad$ Fifth search charater (,) 
1: $44 \quad \mathrm{~F}$

2: $00 \quad$ Exponent of 10

3: 29 Z Loc [ comma ]

10: $\mathrm{Z}=\mathrm{F}(\mathrm{P} 30)$;

1: $00 \quad \mathrm{~F}$

2: $00 \quad$ Exponent of 10

3: $30 \quad$ Z Loc [ term\#1 ]

11: $\mathrm{Z}=\mathrm{F}(\mathrm{P} 30)$

1: $00 \quad \mathrm{~F}$

2: $00 \quad$ Exponent of 10

3: 31 Z Loc [ term\#2 ]

12: $\mathrm{Z}=\mathrm{F}(\mathrm{P} 30)$;

1: $127 \quad \mathrm{~F}$

2: $00 \quad$ Exponent of 10

3: 32 Z Loc [ NR\#1 ]

13: $\mathrm{Z}=\mathrm{F}(\mathrm{P} 30)$

1: $127 \quad \mathrm{~F}$

2: $00 \quad$ Exponent of 10

3: 33 Z Loc [ NR\#2]

14: $\mathrm{Z}=\mathrm{F}(\mathrm{P} 30)$

1: $127 \quad \mathrm{~F}$

2: $00 \quad$ Exponent of 10

3: 34 Z Loc [ NR\#3 ]

15: $\mathrm{Z}=\mathrm{F}(\mathrm{P} 30)$

1: $127 \quad \mathrm{~F}$

2: $00 \quad$ Exponent of 10

3: 35 Z Loc [ NR\#4]

16: $\mathrm{Z}=\mathrm{F}(\mathrm{P} 30)$;

1: $102 \quad \mathrm{~F}$

2: $00 \quad$ Exponent of 10

3: $36 \quad$ Z Loc [f ]

17: Port Serial I/O (P15) ; $\quad$ Send command.

1: $1 \quad$ Reps

2: $01 \quad$ ASCII/RS-232, 1200 Baud

3: 1 Delay (0.01 seconds)

4: $1 \quad$ First Control Port

5: 22 Output Loc [ ctrl_Q ]

6: 15 No. of Locs to Send
Terminate search.

Do not replace.

Termination character (f) 
7: 102 Termination Character

8: 0000 Maximum Characters

9: $100 \quad$ CTS/Input Wait

10: 38 Loc [ Null\#2 ]

11: 1.0 Mult

12: 0.0 Offset

18: End (P95)

End Program 
Sliding Collar Probe Resistance Values

$\begin{array}{ccc}\text { Feet } & \text { Probe \#1 } & \text { Probe \#2 } \\ 0.5 & 525 & 523 \\ 1.0 & 1045 & 1046 \\ 1.5 & 1564 & 1570 \\ 2.0 & 2089 & 2093 \\ 2.5 & 2612 & 2614 \\ 3.0 & 3133 & 3139 \\ 3.5 & 3656 & 3662 \\ 4.0 & 4180 & 4185 \\ 4.5 & 4702 & 4708 \\ 5.0 & 5224 & 5230 \\ 5.5 & 5746 & 5756 \\ 6.0 & 6259 & 6275 \\ 6.5 & 6793 & 6799 \\ 7.0 & 7316 & 7321 \\ 7.5 & 7840 & 7844 \\ 8.0 & 8362 & 8367 \\ 8.5 & 8885 & 8889 \\ 9.0 & 9408 & 9412 \\ 9.5 & 9931 & 9935 \\ 10.0 & 10454 & 10459 \\ \text { Collar Not Installed } & 15808 & 15827\end{array}$

